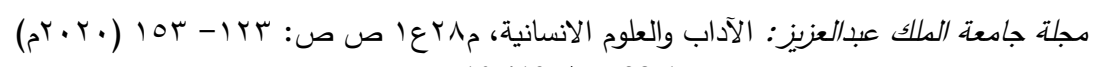

DOI:10.4197/Art.28-1.5

\title{
المناخ الأخلاقي وعلاقته بالتماثل التظيمي لاى أعضاء هيئة التدريس بجامعة الملك عبد العزيز
}

\author{
د. صالج بن علي يعن الله القرني

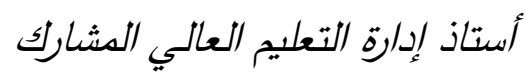

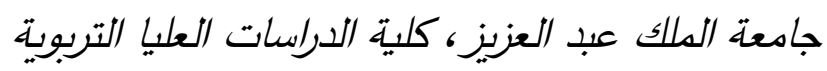

مستخلص. هدفت هذه الدراسة إلى الكثف عن العلاقة بين أنماط المناخ الأخلاقي السائدة بجامعة الملك عبد الكبأ

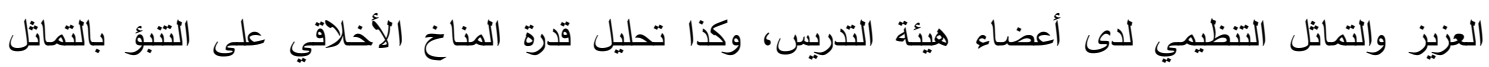

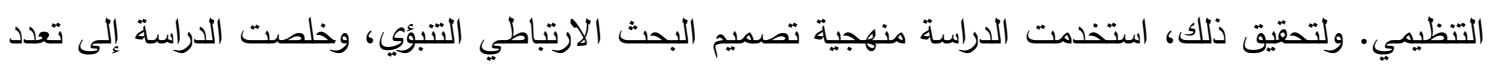

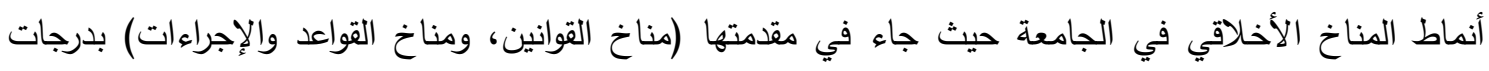

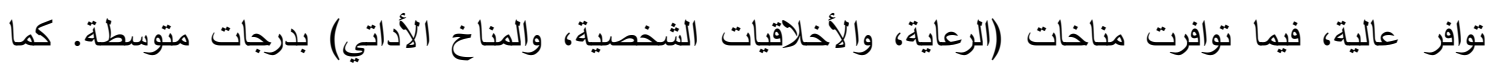

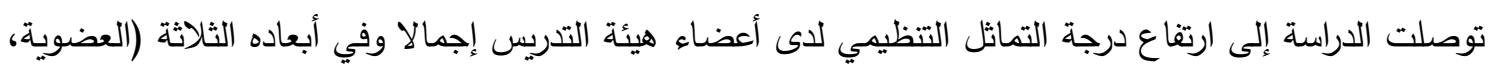

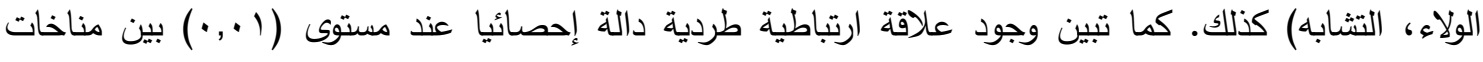

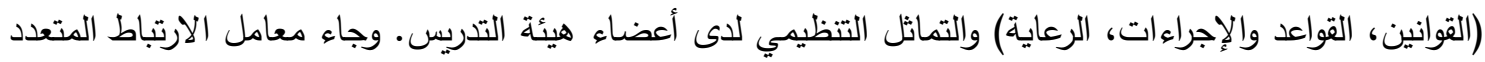

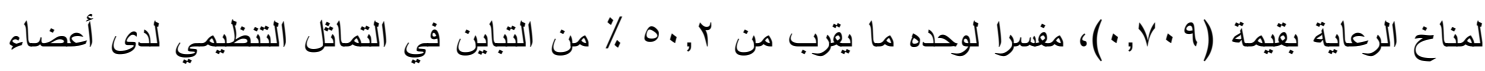

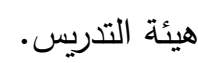
الكلمات المفتاحية: المناخ الأخلاقي، التماثل التنظيمي، أعضاء هيئة التنريس

الخارجي ومحيطها الداخلي كذلك. وقد انعكست آثار هذه التغيرات على سلوكات واتجاهات أفرادها،

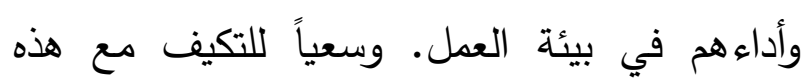
المتغيرات، اتجهت هذه المنظمات متأثرة بالتوجهات

\section{المقدمة}

تواجه المنظمات عامة والمنظمات التعليمية تحديدا العديد من التحديات والصعوبات في إدارة أفرادها، وذلك بسبب التغيرات المتسارعة الحادثة في محيطها 
المنظمة، والمواطنة التنظيمية (VanDick, 2001)، Riketta \& ) والسلوكات المرغوبة في فرق العمل Van Dick, 2005 )، وزيادة الدافعية للعمل، وسلوك لكون الدور الإضافي (Reade, 2001). كذلك للتماثل التتظيمي أهمية في الحياة الوظيفية للعاملين تتمثل في تعزيز الفرد لنفسه واحترامه لذاته، والوصول به لارجة من السمو فوق الذات، وإضفاء معنى مميز

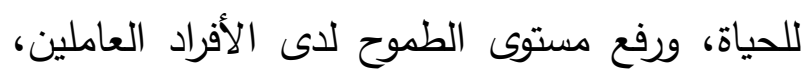
Mael ( ويزيد بدرجة ملفتة من انتماءهم لمنظماتهم .(\& Ashforth, 2001 ونتيجة لهذه الأهمية المتنامية للتماثل التنظيمي فقد وجد طريقه إلى المنظمات التعليمية عموماً

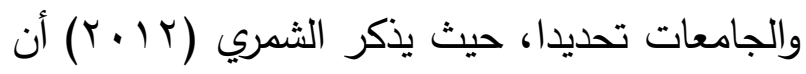
الاهتمام بالتماثل التنظيمي زاد تحديداً في الجامعات،

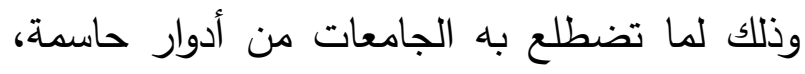
ولكون أعضاء هيئة التدريس هم عوامل نجاحها الأساسية، ومن ثم كان عليها أن تعمل على أن فينه يؤمن أعضاء التدريس فيها وموظفوها برؤيتها وأهدافها وصولاً لحالة من التلاقي والتشابه بين أهدافهم وأهداف الجامعة التي يعملون بها. ولدراسة التماثل التنظيمي في البيئة الأكاديمية في

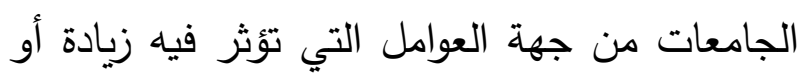
نقصا، ربما يكون من الأجدر البحث في صفة لهنه المناخ الأخلاقي السائد في بيئة العمل نظرا لكون التماثل التنظيمي ينطوي على مضامين وأبعاد قيمية وأخلاقية، ولكونه يؤثر بشكل مباشر على سلوكات
التي أفرزها علم النفس الإيجابي إلى دراسة سلوكات

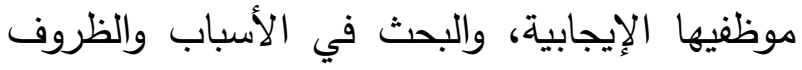

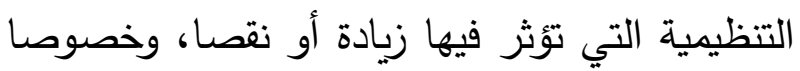
تلك العوامل التتظيمية التي تتصل بالأبعاد الأخلاقية في بيئة العمل. - الم وفي الآونة الأخيرة زادت وتيرة الدراسات والأبحاث التي تتبع السلوكات التظيمية الإيجابية وسبل تتميتها في أوساط العاملين، وقد حظي سلوك التماثل التنظيمي بنصيب وافر من البحث والدراسة باعتباره

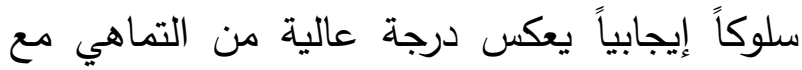
المنظمة والتباهي بها، حيث أثنار ميل وأشفورث (Mael \& Ashforth,1989, p.10) التنظيمي في جوهره ينطوي على "إدراك بالتوحد مع المنظمة والانتماء إليها، حيث يعرف الفرد نفسه من خلال المنظمة التي يعمل بها". وهو أي التماثل

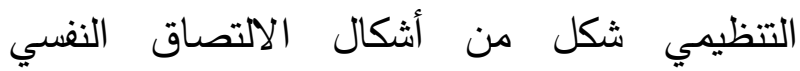
والوجداني بالمنظمة، يحدث عندما يتشرب أعضاء تلك المنظمة السمات المعرّفة لها، ومن ثم يتم تبنيها على أنها سماتهم الذاتية (رشيد، +. ץ)، كما يتولد لديهم شعور بأنهم جزء أصيل في منظمتهم، وتربطهم بها رابطة نفسية قوية تظهر جلية في رغبتهم القوية في البقاء فيها في الأوقات الجيدة والعصيبة على حد (Mael \& Ashforth, 1992; Meyer \& سواء .Allen,1997; Scott \& Lane,2000) ومن الناحية التنظيمية تبرز أهمية التماثل التنظيمي في تحقيق بعض النتائج التنظيمية كالرضا الوظيفي (Abrams \& De Moura, 2001)، ونية البقاء في لبكيل 
ثقافة تتظيمية مكرسة للقيم الأخلاقية، والسلوك الأخلاقي ومحفز لدافعية عناصرها البشرية، والتزامهم بتحقيق أهدافها. ونظراً لكون أنماط المناخ الأخلاقي التي تسود

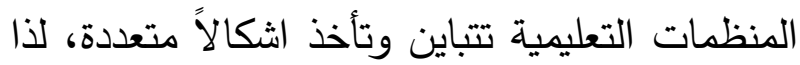
فإنه من الطبيعي أن ينعكس المناخ الأخلاقي السائد في أي منظمة تعليمية على سلوكات أفرادها

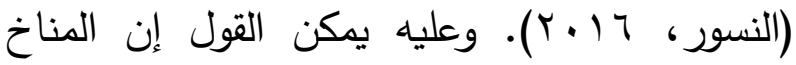
الأخلاقي السائد في بيئة العمل بأنماطه المتعددة له له علاقة بسلوكات العاملين في بيئة الععل واتجاهاتهم نحو منظماتهر التي يعملون بها، وانتماءهم لها واندماجهم معها، وارتباطهم بها؛ وما ذلك إلا لما يحدثه من تأثير في ظروف العمل، وطبيعة العلاقات بين الرؤساء والمرؤوسين، وطرق الاتصال بينهم، ومدى مشاركة العاملين وإدلائهم بآرائهم في مشكلات وتحديات بيئة العمل المتجددة، بالإضافة إلى ما يمكن أن يحدثه من تأثير مباشر أو غير مباشر

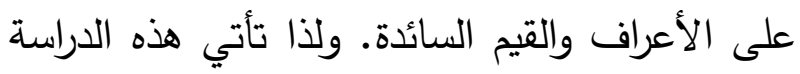
كمحاولة للتعرف على أنماط المناخ الأخلاقي السائدة في البيئة الجامعية ممثلة في هذه الدراسة في حالة

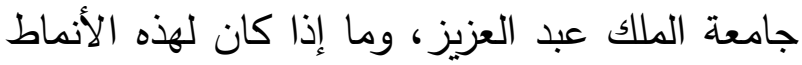
علاقة بالتماثل التنظيمي لدى أعضاء هيئة التدريس.

\section{مثكلة الاراسة وأسئلتها}

أظهرت بعض الدراسات أن المناخات الأخلاقية السائدة في الجامعات تتباين، وتأخذ أشكالاً متعددة، تبعاً لنوعية القادة الإداريين، وأسلوب
العاملين في المنظمات، حيث توصل الباحثون إلى أن سلوكات العمل لدى العاملين تعتمد على درجة الدعم التي يوفرها لهم المناخ الأخلاقي حيث يثير لعني شنايدر وريتشرز (Schneider \& Reichers,1983) إلى أن المناخ الأخلاقي يحدد ويوجه سلوكات

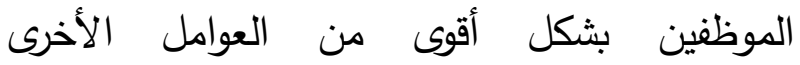
كالاحتياجات والدوافع والرغبات الفردية. وبالمثل، يشير ويبر (Weber, 1995) إلى أن القيم الأخلاقية موجودة ضمنيا في المنظمات، وهي التي تمكن العاملين من اتخاذ قرارات ومواقف وسلوكيات أخلاقية معينة. كذلك يؤكد العديد من الباحثين أنه

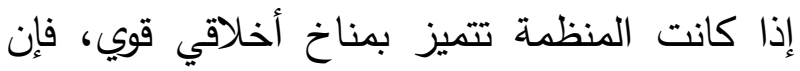
موظفيها سيعيرون الأخلاق اعتبارا قويا لكونها متوقعة ومطلوبة وتجري مكافأتها في مكان عملهم، لا بل ويكونون أقل عرضة للانخراط في السلوكات الأخلاقية المعيبة ( Martin \& Cullen, 2006; Peterson, 2002a; Wimbush, Shepard \& (Markham, 1997 ). وفي ذات السياق تثير دروزة والقواسمي (ع الـr) أن للمناخ الأخلاقي صلة بالمشاعر التي تتتاب العاملين تجاه ذواتهم ومنظمتهم. ولما كانت الجامعات تهدف إلى بناء الإنسان المتوازن، والمتعلم معرفيًا ومهارياً ووجدانيًا، بحيث يكون متفاعلا مع بيئته ومجتمعه في إطار القيم والمبادئ الأخلاقية، وقواعد السلوك الأخلاقي

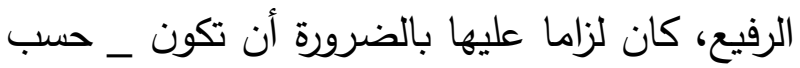

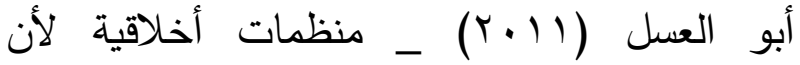
نهوضها برسالتها بكفاءة وفاعلية، يفرض امتلاكها 
مثل الالتزام التنظيمي \& Cullen, Parboteeah \&

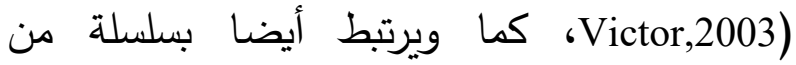
السلوكات السلبية مثل اللامبالاة، والتأخر ، والتغيب

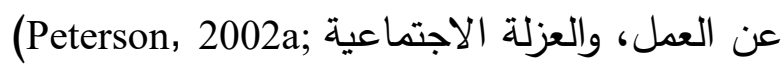
(Peterson, 2002b) هل يمكن أن يكون للمناخ الأخلاقي في البيئة الأكاديمية علاقة بسلوكات واتجاهات أعضاء هيئة

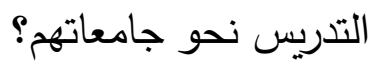

ونظرا لكون التماثل التتظيمي أحد السلوكات الإيجابية التي حظيت باهتمام الباحثين والممارسين في الآونة الأخيرة باعتبار النتائج التنظيمية الإيجابية التي تتمضض عنه، لذا تدور مشكلة هذا البحث في المتغيرات التنظيمية ذات الأهمية التي يمكن أن تقدم

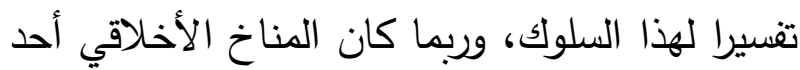
هذه المتغيرات التي يجدر بنا دراستها وبحث ظاهرة التماثل التظيمي في سياقها. ومن هنا فالدراسة الحالية تترسم هذا الاتجاه في محاولة لاستكثاف العلاقة بين المناخ الأخلاقي كما يتصوره أعضاء

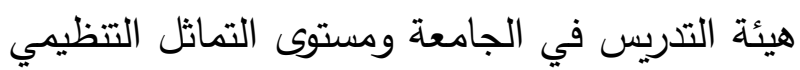

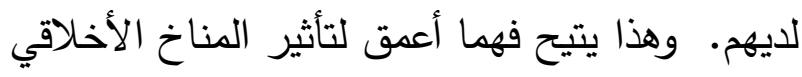
المدرك على سلوك التماثل التنظيمي لأعضاء هيئة التدريس، كما ويتسنى من خلال ذلك للقيادات الأكاديمية إدراك مدى تأثير المناخ الأخلاقي على لفى لانى ديمومة وفاعلية الحياة التنظيمية في الجامعة عموماً. ونظرًا لحداثة مفهوم المناخ الأخلاقي على المستوى المحلي والعربي وقلة الدراسات التي تتاولته (الصباغ
القيادة، وطبيعة العلاقات القائمة بين الأفراد العاملين، وبنود الدساتير الأخلاقية التي تحكم العمل

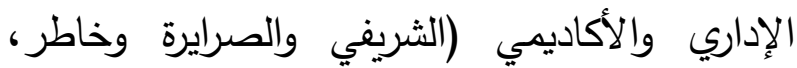

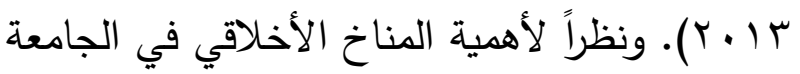
بوصفه عاملا مؤثرا في السلوك التنظيمي لأعضاء هيئة التدريس والعاملين، وفي عملية صنع القرارات والإجراءات والممارسات الإدارية المختلفة (الشريفي

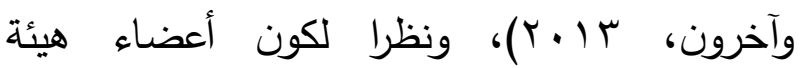
التدريس هم موظفو الخطوط الأمامية في مؤسسات لونات التعليم العالي؛ إذ أن مهام العمل التي يؤدونها كل يوم لها تأثير مباشر على قدرة المؤسسة على تلبية توقعات أصحاب المصلحة، وسواء كان صاحب لون لهاب المصلحة هو الطالب أو أحد جهات المجتمع المحلي

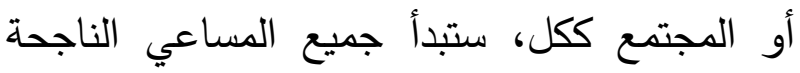
على أيدي أعضاء هيئة التدريس في الخطوط الأمامية. ولذا كان من الأهمية بمكان ضمان تماثلهم وارتباطهم التنظيمي بجامعاتهم وتوحدهم القيمي معها. وهذا يحمل للقيادات الأكاديمية إثارات ومضامين مهمة في إعطاء أولوية واهتمام كافيين للجوانب الإجرائية والإدارية ذات الأبعاد الأخلاقية والتي يمكن من خلالها الحصول على نتائج وعوائد ذات قيمة على صعيد السلوكات والاتجاهات الإيجابية لدى أعضاء هيئة التدريس أو الحد من الممارسات والسلوكات غير المقبولة لديهم.

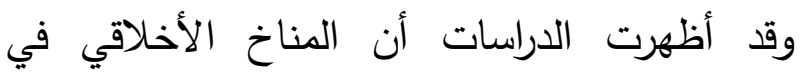
المنظمة يرتبط مباشرة بالسلوكات الإيجابية للعاملين 
التظيمي لديهم تبعاً لاختلاف النوع، وسنوات

الخبرة؟

\section{أهمية الاراسة:}

تكتسب الدراسة أهميتها من كونها تتناول موضوع المناخ الأخـاقي والذي أضحى أحد المتغيرات التظيمية الحاسمة في بيئة العمل، وذلك فيما يتصل بإدارة ومعالجة القضايا والمعضلات الأخلاقية، وتحديد معايير السلوك الأخلاقي الصحيح، والتنبؤ بالعديد من السلوكات والنواتج التنظيمية. كما تبرز أهمية الدراسة من كونها تتناول مفهوم التماثل التظظيمي، وهو أحد الموضوعات التي لم تتل حظها من البحث والدراسة في البيئة العربية والمحلية على حد سواء. ومن المعلوم أن التماثل التنظيمي هو أحد السلوكات الإيجابية التي تتطوي على مضامين قيمية عليا، ولذا تسعى المنظمات عالية الأداء إلى تبنية وترسيخه في أوساط موظفيها لكونه يعزز تماسك المنظمات، ويسهم في زيادة الانتاجية المترتبة على زيادة الولاء والانتماء لتلك المنظمات، وبفقدانه أو ضعفه تظهر حالات الترك، والانسحاب، والانتقال الوظيفي. ومن الناحية العملية يؤمل أن تسهم الدراسة الحالية في سد النقص في دراسات المناخ الأخلاقي في المكتبة العربية عموماً والمحلية تحديدا، كما يتوقع أن تكون هذه الدراسة محفزة لمزيد من الأبحاث المستقبلية حول المناخ الأخلاقي في مؤسسات

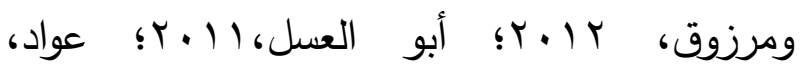
1 0 الواحدة، ولعدم توافر دراسات سابقة في موضوع المناخ الأخلاقي وعلاقته بالتماثل التنظيمي لدى أعضاء هيئة التّري في البيئة الجامعية، تحددت مشكلة الدراسة في السؤال الرئيس التالي: ما علاقة أنماط المناخ الأخلاقي السائدة في جامعة الملك عبد العزيز بالتماثل التظظيمي لاى أعضاء

هيئة التدربس؟

ويتفرع عن السؤال الرئيس الأسئلة الفرعية التالية: () ما أنماط المناخ الأخلاقي السائدة في جامعة الملك عبد العزيز من وجهة نظر أعضاء هيئة

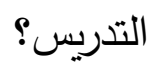

r) ما مستوى التماثل التظيمي لدى أعضاء هيئة التدريس بجامعة الملك عبد العزيز من وجهة

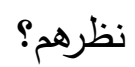

r) هل توجد علاقة ارتباطية ذات دلالة إحصائية بين تصورات أعضاء هيئة التدريس حول أنماط المناخ الأخلاقي السائدة في الجامعة ومستوى التماثل التنظيمي لديهج؟ §) هل توجد فروق ذات دلالة إحصائية بين تصورات أعضاء هيئة التدريس لأنماط المناخ الاخلاقي السائدة في الجامعة تبعاً لاختلاف النوع، وسنوات الخبرة؟ 0) هل توجد فروق ذات دلالة إحصائية بين تقديرات أعضاء هيئة التدريس لمستوى التماثل 
الناحية الأخلاقية، وكيف يتم التعامل مع القضايا المتعلقة بالانحرافات عن تلك السلوكيات المتوقعة في المنظمة. وعليه نفهم أن المنظمات جهات فاعلة اجتماعيا من حيث هي مسؤولة عن السلوكيات الأخلاقية أو غير الأخلاقية لموظفيها. وحسب كولين ورفاقه (Cullen, Victor \& Stephens,1989) فالمناخ الأخلاقي هو إدراك لما يشكل السلوك

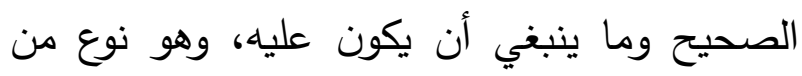
الإدراك الذي يمثل آلية نفسية يتم من خلالها إدارة

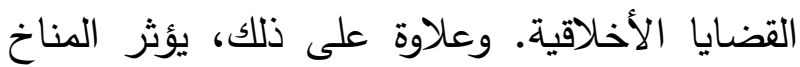
الأخلاقي على صنع القرار والسلوك اللاحق استجابة

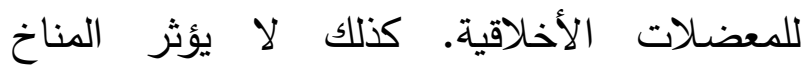
الأخلاقي فقط على القضايا التي يعتبرها أعضاء

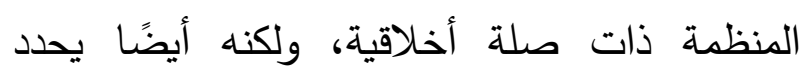
المعايير الأخلاقية التي يستخدمها الأعضاء لفهم

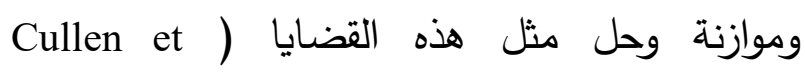
.(al.,1989 وتذكر معظم الأدبيات التي تتاولت المناخ الأخلاقي أن أبرز الإسهامات كانت في أواخر الثمانينات من الادبيات القرن العشرين الميلادي على يد كل من فكتور

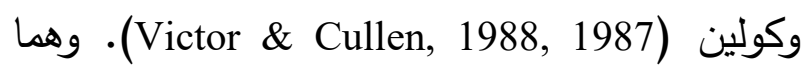
أول من تحدثا عن نظرية المناخ الأخلاقي، حيث أشارا إلى أنه لابد للمنظمة أن تلتزم بالمسؤولية تجاه

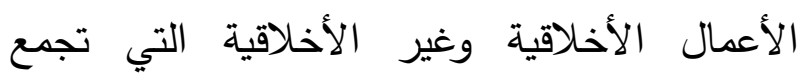
الموظفين ضمن نطاق منظمة واحدة والتي تثكل مناخ العمل الأخلاقي فيها.
التعليم العالي، وكذا محفزة لدراسات تتناول التماثل التنظيمي في سياق متغيرات تتظيمية أخرى. ويتوقع أن تسهم هذه الدراسة في تزويد إدارة جامعة لفئي

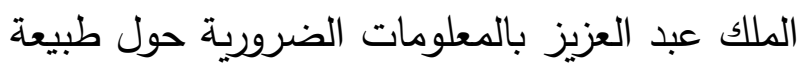
المناخ الأخلاقي السائد فيها، مما يساعد في اتخاذ القرارات السليمة التي ترسخ لأنماط المناخ الأخلاقي الإيجابية. كما يؤمل أن تفيد هذه الدراسة قطاعات أخرى في الجامعة تهتم بتتمية وتدريب الموارد

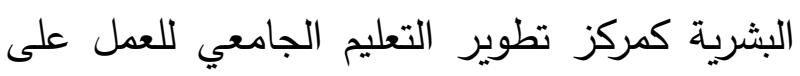
تصميم وتخطيط برامج تدريبية حول آليات تعزيز وتتمية التماثل التنظيمي في أوساط أعضاء هيئة تئة التدريس والموظفين.

\section{الخلفية النظرية للاراسة}

المناخ الأخلاقي: يعرف فيكتور وكولين المناخ الأخلاقي بأنه " التصورات المشتركة للعاملين في المنظمة حول السلوكيات التي تعتبر صحيحة في منظمتهم،

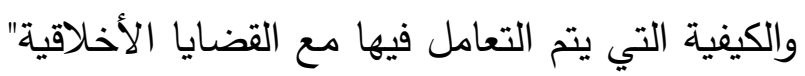
(Victor \& Cullen, 1988,101; Victor \& Cullen, Sims بأنه: "فهم مشترك أو (1987,p. 52) كما عرفه مجموعة مشتركة من الإدراكات والاستتناجات عن السلوك الصحيح، والكيفية التي يتم بها معالجة

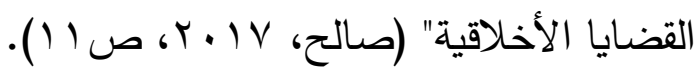
وهنا يتضح أن المناخ الأخلاقي يشير إلى تلك الك الكان المدركات والتصورات المشتركة لدى العاملين في

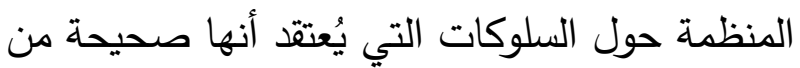


الفردي (الذاتي)، والمستوى المحلي (داخل

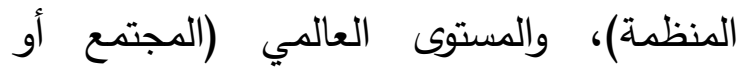

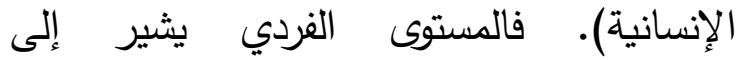
المعتقدات الثخصية لدى الفرد باعتبارها المرجع

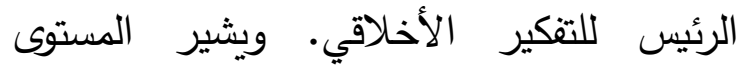
المحلي إلى القيم والقواعد داخل المنظمة كمرجع للتعليل والتفكير الأخلاقي. أما المستوى العالمي فيشير إلى القوانين والتقاليد السائدة في المجتمع Cullen et ) والمعايير الأخلاقية للمهنة al.,2003; Martin \& Cullen,2006; Victor \&

.(Cullen, 1988

ووفقا للإطار النظري للنموذج، فعن تقاطع المستويات الثلاثة للمعايير الأخلاقية مع مقاربات التحليل الثلاثة، نتج لدى فيكتور وكولين (9Nv) تسعة أنواع مختلفة من المناخ الأخلاقي: المصلحة لهدين الذاتية، مصلحة الشركة، الكفاءة، الصداقة، مصلحة

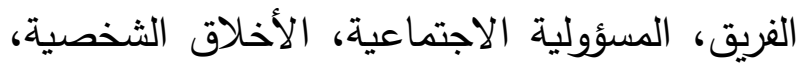
القواعد والإجراءات، والقوانين والمدونات المهنية (الجدول رقم (). وللتحقق من صحة هذا التصنيف

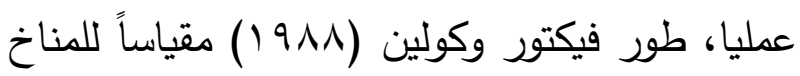
الأخلاقي يتكون من تسعة أنماط محتملة للمناخ الأخلاقي عن طريق جمع بيانات تجريبية من دراسة

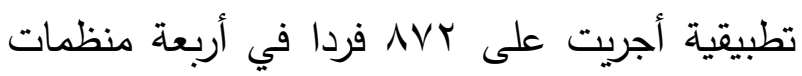
مختلفة، وقد أفرز هذا التحقق خمسة مناخات أخلاقية وهي :المناخ الأداتي أو ما يطلق علية مناخ الوسائل والذي يركز على تعظيم الفائدة الذاتية ؛ ومناخ الرعاية الذي يتمحر حول الاهتمام برفاهية
Victor ( ووفقا للنموذج الذي قدمه فكتور وكولين (and Cullen, 1988; Victor and Cullen, 1987 لتفسير المناخ الأخلاقي، يتضدن الإطار النظري لهذا النموذج بعدين هما:

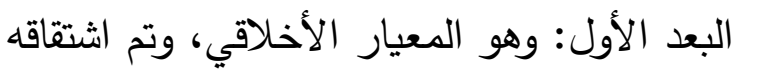
من نظرية كولبيرغ (Kohlberg,1984) حول الفلسفة الأخلاقية والتطور الأخلاقي المعرفي، ويتكون هذا البعد من ثلاثة مستويات للمعايير الأخلاقية المستخدمة في صنع القرار، وهي لبكن الأنانية أو حب الذات egoism، والخيرية benevolence الأنانية إلى التركيز على المصلحة الذاتية والسلوكيات الساعية لتعظيمها؛ ويشير الإحسان إلى الاهتمام بإرضاء مصالح أكبر عدد ممكن من الناس؛ أما المبادئ فيتعلق باستيعاب الماء المعايير والمعتقدات العالمية من قبل أعضاء المنظمات، والرغبة في عمل ما هو صحيح بغض النظر عن النتائج المحتملة أو تأثير تلك فو Cullen et al.,2003; ) النتائج على الآخرين Martin \& Cullen,2006; Victor \& Cullen, .$(1988$ البعد الثاني: وهو التحليل المكاني، والمستمد من النظريات الاجتماعية للأدوار والمجموعات المرجعية في المنظمات (Merton, 1957)، ويشير إلى ثلاثة مواقع للتحليل تستخدم كمرجعية

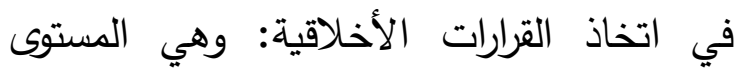


Martin and Cullen, ) الآخرين؛ ومناخ الاستقلالية الذي يغِب الاهتمام نقدية حديثة لمارتن وكولين والالتزام بالمعتقدات الأخلاقية الثخصية؛ ومناخ 2006) صحة هذا التصنيف القائم على وجود خمسة القواعد الذي يركز على الالتزام بسياسات المنظمة أنواع من المناخ الأخلاقي، والتي توصل إليهات اليها فيكتور

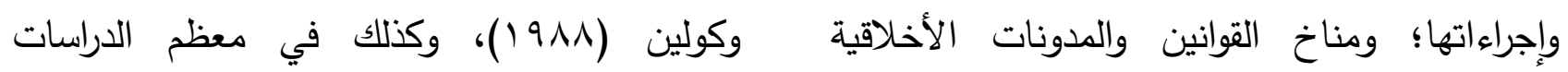

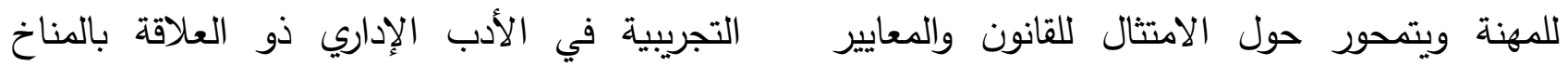
المهنية ( الجدول رقم r). وقد أثبتت مراجعة تحليلية الأخلاقي.

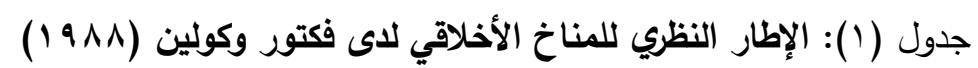

\begin{tabular}{|c|c|c|c|}
\hline \multicolumn{3}{|c|}{ مستوى التحليل } & \multirow{2}{*}{ المعايير الأخلاقية } \\
\hline عالمي & محلي & فردي & \\
\hline الكفاءة & ربح الشركة & المصلحة الثخصية & الأنانية \\
\hline المسؤولية الاجتماعية & مصلحة الفريق & الصداقة & الخيربـة \\
\hline القواعد ومعايير المهنة & قواعد المنظمة والإجراءات & المعتقدات الثخلية & المبادئ \\
\hline
\end{tabular}

(Martin and Cullen, 2006)

جدول(ץ): الإطار التطبيقي لأنماط المناخ الأخلاقي لاى فكتور وكولين (1911)

\begin{tabular}{|c|c|c|c|}
\hline \multicolumn{3}{|c|}{ مستوى التحليل } & \multirow{2}{*}{ المعايير الأخلاقية } \\
\hline عالمي & محلي & فردي & \\
\hline \multicolumn{3}{|c|}{ الدناخ الأداتي "ي الوسائل" } & الأنانية \\
\hline \multicolumn{3}{|c|}{ الرعآية } & الخيرية \\
\hline مناخ القاونيلنين والمدونات & مناخ القواعد والإجراءات & 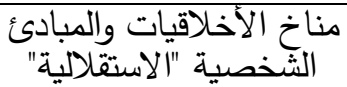 & المبادئ - ائ \\
\hline
\end{tabular}

المصدر: (Martin and Cullen, 2006)

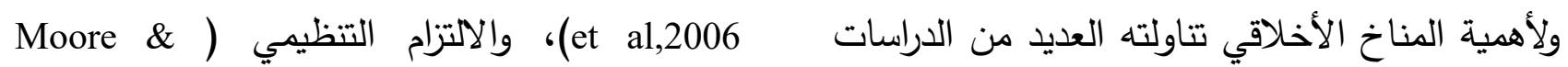

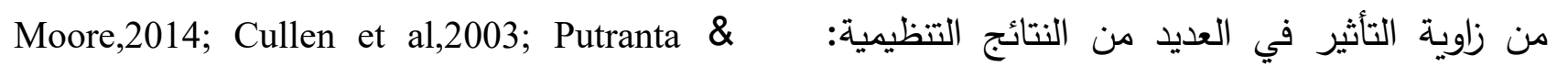

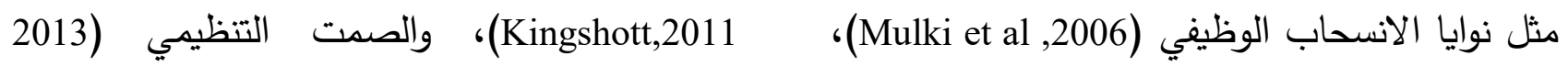

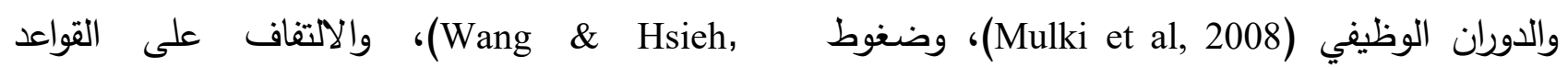

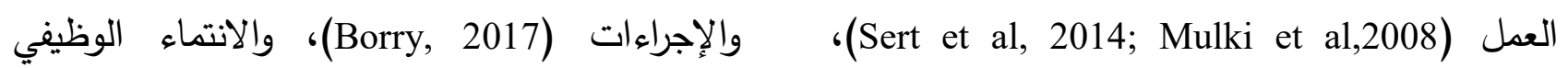

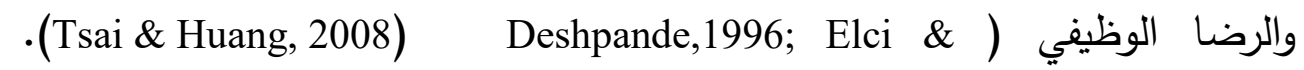
وعطفا على ما سبق، يمكن القول إن المناخ

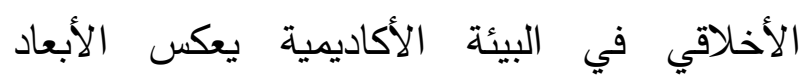
Alpkan,2009; Joseph \& Deshpande,1997;Tsai (\& Huang,2008; Ulrich et al,2007). وتتاولت \& دراسات أخرى تأثيره في الثقة في المشرفين ( Mulki 
بذات الصفات التي يعتقد أنها تمثل هوية المنظمة" (Dutton et al.,1994, p.239)

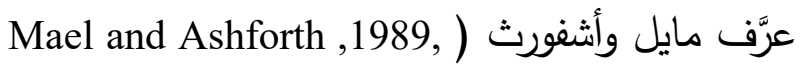

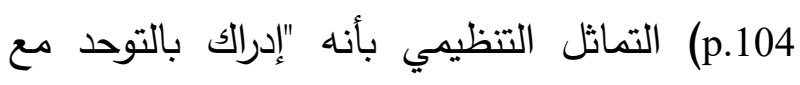

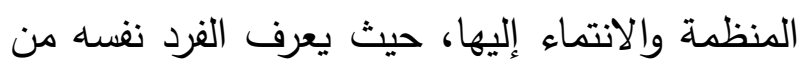

خلال المنظمة التي يعمل بها".

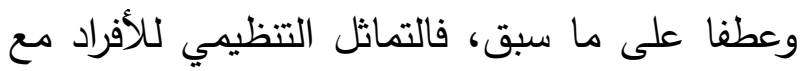

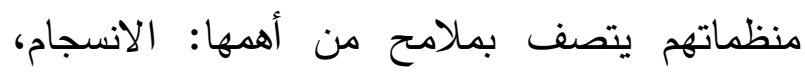

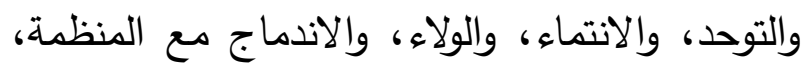

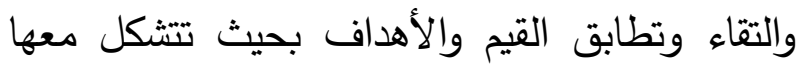
رابطة نفسية قوية بين الفرد والمنظمة. وتأسيسا على ولى لفئ

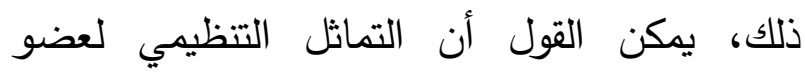
التدريس مع جامعته يتمثل في ذلك الثعور الداخلي لاى عضو هيئة التدريس بوجود روابط جذب نفسية واجتماعية تربطه بالجامعة، ينتج عنها تثابه في

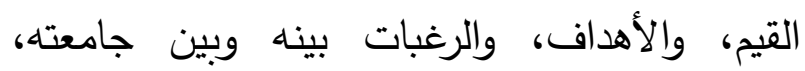

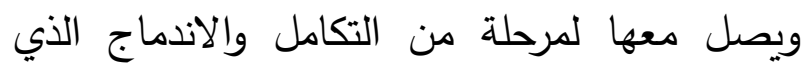
يجعله يعرف نفسه من خلال الجامعة.

ويُنظر إلى التماثل التنظيمي على أنه ذو صلة بمجموعة متتوعة من النتائج التنظيمية المرغوبة

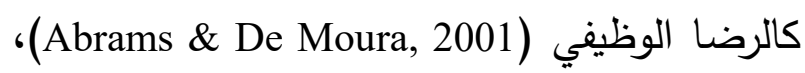
ونية البقاء في المنظمة، وسلوك المواطنة التنظيمية (VanDick, 2001)، وزيادة الدافعية للعمل، وأداء (Reade, مهام أكثر من تلك التي يتطلبها الدور، ولادهاه (2001، وسلوك المواطنة التنظيمية، والاستعداد للتعاون مع الآخرين (Van Dick,2007)، وانخفاض وله
الأخلاقية لثقافة الجامعة، ويشكل شخصية المؤسسة الجامعية، ويدخل في تكوينها وهويتها وشكلها التنظيمي، ويحدد ويوجه سلوكات أفرادها. ويستدل

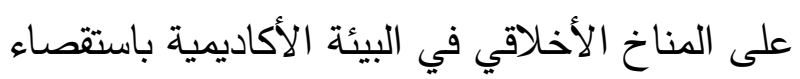

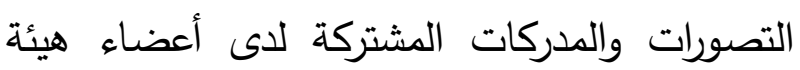
التدريس حول الممارسات والسلوكات التي يُعتقد أنها صحيحة من الناحية الأخلاقية والتي لها صفة الحاكمية على تصرفات الأفراد وسيرورة العمل الإداري والأكاديمي، والكيفية الإجرائية التي يتم من خلالها التعامل مع الانحرافات عن تلك السلوكيات المتوقعة ومعالجتها في الجامعة.

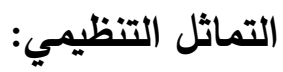
أَضحى التماثل التنظيمي في الوقت الراهن أحد

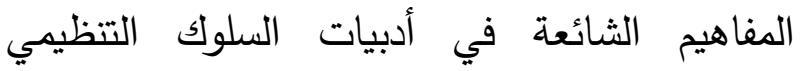
لاستكثاف الارتباط النفسي للموظفين بمنظماتهم (Ashforth, Harrison \& Corley, 2008) تناولته الأدبيات من عدة زوايا ولكنه بشكل عام يشير إلى وجود صلة نفسية بين الفرد والمنظمة Ashforth \& Mael, 1989; Edwards, 2005; ) Edwards \& Peccei, 2010; Mael \& Ashforth, .(1992; Meyer, Becker \& Van Dick, 2006 ويعرف التماثل التظيمي بأنه "ارتباط نفسي بين الفرد والمنظمة يتمثل في شعور الفرد برابطة عاطفية معرفية عميقة مع المنظمة تجعله يحدد ويعرف ذاته

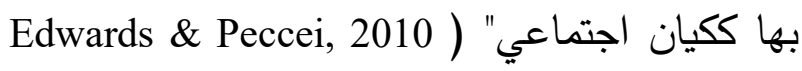
p.30). أو هو " الدرجة التي يعرف العضو نفسه 
Edwards, 2005; ( أخرى خلاف التماثل التتظيمي (Edwards \& Peccei, 2007 دراسة مائل آشفورث (Mael \& Ashforth,1992)، وهي إحدى المحاولات الرائدة في هذا الصدد حيث توصلت إلى نتائج مهمة على صعيد المعرفة بأدبيات التماثل التنظيمي من جهة تحرير المفهوم نظريا، وكذلك من الناحية التطبيقية حيث قدمت الدراسة مقياسا يعد من أكثر المقاييس شيوعا في استقصاء التماثل التتظيمي. وكانت هذه الدراسة أحد مصادر المعرفة الرئيسة حول الموضوع للدراسات التي أجريت لاحقا ( Edwards \& Edwards, 2012; Morgeson \& Hekman, 2012; ‘Johnson \& Smith, 2011; Vuuren, Koovor-Misra ( Jong, 2010 Beelen Miller et al, ) دراسة مهمة أجراها ميلر ورفاقها 2000)، وهدفت إلى البحث في الأبعاد الداخلية لمقياس التماثل التظيمي الذي أعده تشيني من خلال مجموعة من اختبارات (Cheney, 1983)

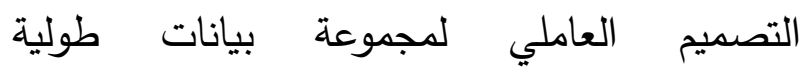
ومستعرضة، وتوصلت إلى وجود r ا فقرة ترتبط وتسهم بشكل معنوي في المقياس. على الصعيد العربي أجريت بعض الدراسات منها ما لماست ذهب لقياس درجة التماثل التنظيمي كدراسة رشيد

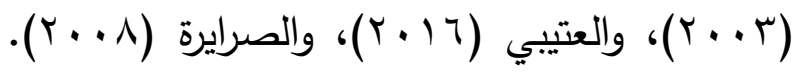

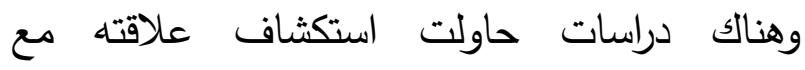
متغيرات أخرى مثل الأمن والأداء الوظيفي (الصرايرة

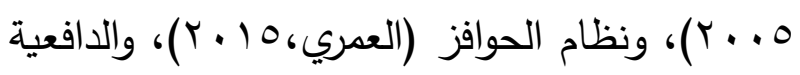

نوايا الدوران الوظيفي (Cole and Brunch, 2006)، والرضا الوظيفي، وسلوك الدور الإضافي .(Holzinger, 2007)

بالنسبة للأفراد، يسهم التماثل التنظيمي في إثباع الاحتياجات الفردية مثل الحاجة للأمن، والانتماء، وتعزيز الذات، وإضفاء معنى للحياة الوظيفية (Pratt, 1998)، كما أنه ينمي الإحساس بالهوية وتعريف الذات ( Van Ashforth \& Mael,1989 (Knippenberg \& Van Schie,2000; الدراسات أنه كلما كانت تماثل الأفراد أقوى مع مؤسساتهم، زادت احتمالية تصرفهم وفقًا لأهداف المنظمة وتوقعاتها (Dutton et al.,1994)، وزاد لديهم الاستعداد للبقاء مع المنظمة (Reade,2001). ونظرا لهذه الأهمية المتزايدة للتماثل التنظيمي على الصعيد التنظيمي، كانت هناك محاولات عديدة لإجراء دراسات تستهدف بناء مقاييس لاستكثاف هناف هذه الظاهرة التنظيمية والنفسية في بيئة العمل. ويعد المقياس الذي طوره تشيني (Cheney, 1983)

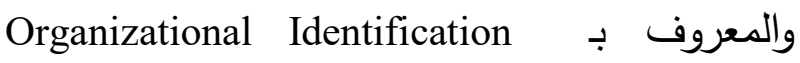
Questionnaire (OIQ) على ثلاثة أبعاد (الولاء والتثابه والعضوية) أحد المقاييس المستخدمة على نطاق واسع في دراسات

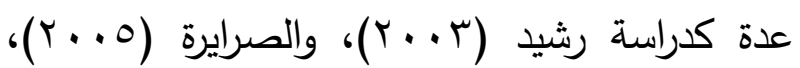

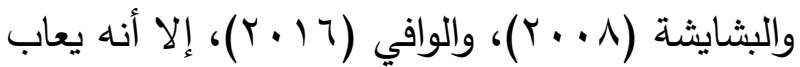
على هذا المقياس كونه يقيس مكونات تنظيمية 
Reichers,1983) كما أظهرت الأبحاث أن المناخ الأخلاقي أحد العوامل التي تتنبأ بالسلوك الوظيفي

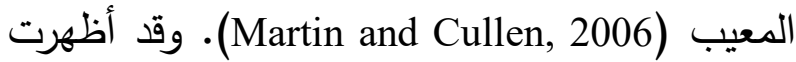
الدراسات أن المناخ الأخلاقي في المنظمة يرتبط مباشرة بالسلوكات الإيجابية العاملين مثل الالتزام التنظيمي (Cullen et al. 2003). كما ويرتبط أيضا بسلسلة من السلوكات السلبية للعاملين مثل اللامبالاة، والتأخر، والتغيب عن العمل، والعزلة الاجتماعية .(Peterson, 2002a; Peterson, 2002b ) وفي سياق متصل تثير الأدبيات أن المناخ الذي يسوده روح الإيثار والتعاون والمسؤولية يؤثر إيجابياً

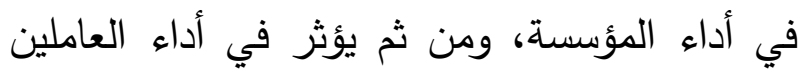
فيها؛ مما يحفزهم على توقيع عقد غير مرئي مع المعائ المنظمة يجسد الرضا والانتماء والمواطنة. كنلك تئك للمناخ الأخلاقي أثر في الششاعر التي تنتاب العاملين تجاه ذواتهم ومنظماتهم؛ إذ يدفعهم إلى أداء الأعمال المناطة بهم بإخلاص وانتماء (دروزة إلهاء والقواسمي، 1 ( ب).

وبناء على ما سبق، يبرز هذا السؤال: هل يمكن أن يكون للمناخ الأخلاقي في البيئة الأكاديمية علاقة بالتماثل التنظيمي لدى أعضاء هيئة التدريس؟ وهل

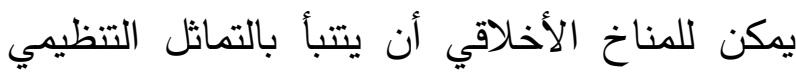
لديهج؟ وعليه فالدراسة الحالية وفق النموذج أدناه تحاول استكثاف العلاقة بين أنماط المناخ الأخلاقي في الجامعة والتماثل التظظيمي لاى أعضاء هيئة

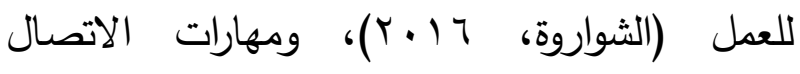

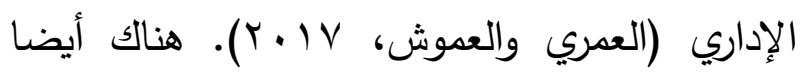
دراسات ذهبت إلى دراسة تأثير بعض العضاكل العوامل التنظيمية في التماثل التتظيمي مثل العدالة التنظيمية

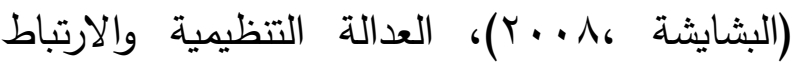

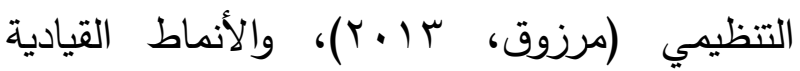

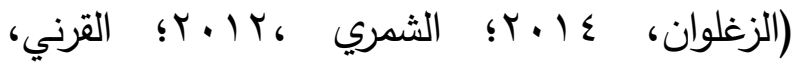

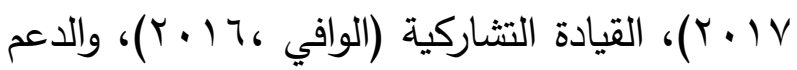
التظظيمي وتكنولوجيا الأداء البشري (العقلا، 10 ب r). ومما سبق، يظهر أن التماثل التظيمي ظاهرة مرغوبة، لها نتائج إيجابية على الصعيدين الفردي التيات

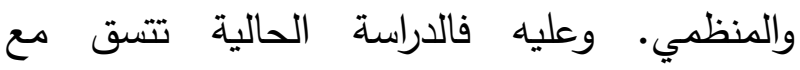
الدراسات أعلاه في كونها تحاول الكثف عن والع العن التماتل التنظيمي ولكن في سياق العوامل ذات الصلة

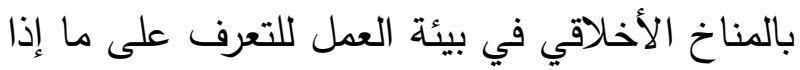
كان لهذه العوامل قدرة تنبؤية بحالة التماثل التتظيمي لاى أعضاء هيئة التدريس باعتبارهم المجتمع لتاني المستهدف في هذه الدراسة. المناخ الأخلاقي والتماثل التنظيمي تشير الأدبيات أن المناخ الأخلاقي يحتوي مضامين وإشارات توجه سلوك الموظف وتعكس الطابع الطابع

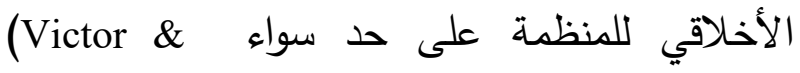
(Cullen, 1987) كما يزعم شنايدر وريتشرز أن الأن المناخ الأخلاقي يحدد ويوجه سلوكات الموظفين بشكل أقوى من العوامل الأخرى كالاحتياجات

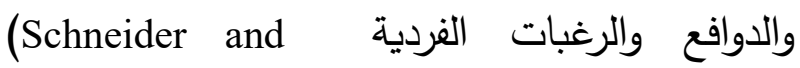


التدريس فيها، لتحديد الأنماط ذات القدرة التتبؤية العالية بهذا السلوك.

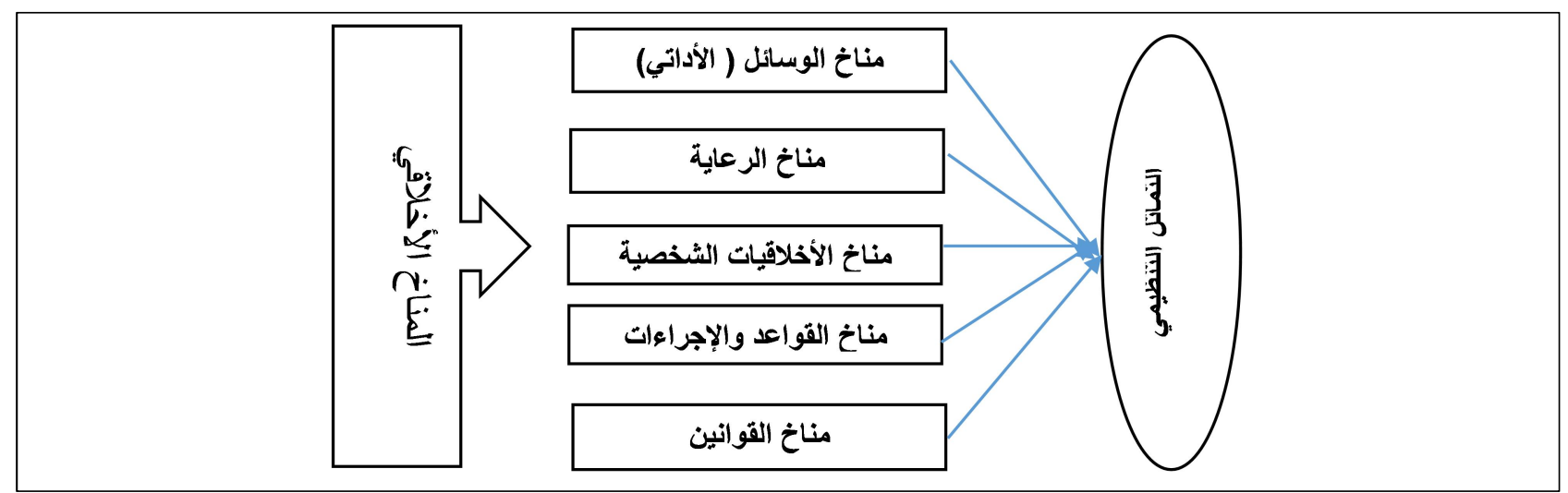

الثكل (1) - نموذج تصوري للدراسة

مستوى التماثل التظيمي للى أعضاء هيئة التدري،

$$
\text { ثم أجري الاختبار الارتباطي }
$$

للكثف عن العلاقة الارتباطية بين أنماط المناخ الإنياخ

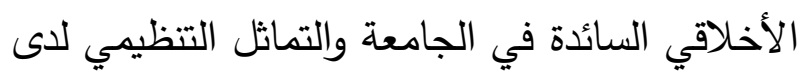
أعضاء هيئة التدري. وبعد ذلك، أجري تحليل

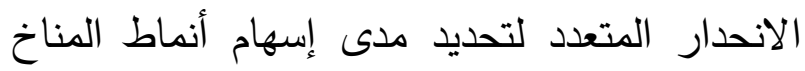

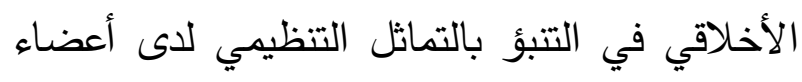
هيئة التدريس.

مجتمع الدراسة:

يتمثل مجتمع هذه الدراسة في جميع أعضاء هيئة التدريس في جامعة الملك عبد العزيز بجدة في

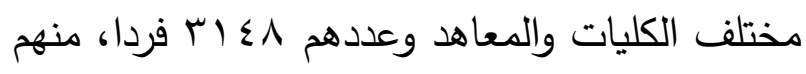
(1V90) من الذكور و (ror (1) من الإناث، وفقاً للإحصاءات المتوافرة على البوابة الإلكترونية

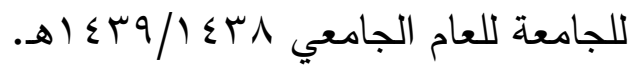

طريقة وإجراءات الاراسة

منهج الاراسة:

استخدمت هذه الدراسة الكمية تصميم البحث

Correlational Prediction الارتباطي التنبؤي Research Design المناخ الأخلاقي التي لديها القدرة على التتبؤ لهات بالتماثل التتظيمي لأعضاء هيئة التدريس. وفي مثل

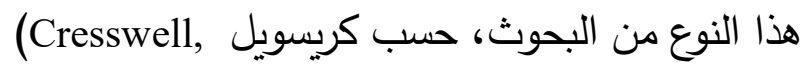
(2012، يستخدم الباحثون الاختبارات الارتباطية

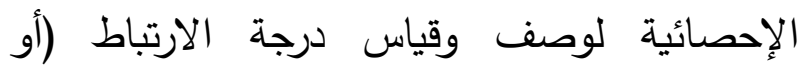

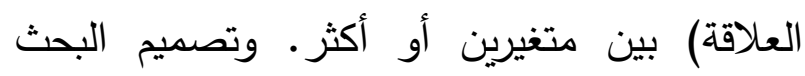
التنبؤي تصميم ارتباطي في أساسه، لتحديد المتغيرات التي ستتنبأ بنتيجة أو معيار معين فين فئي (Cresswell, 2012). ولإجراء هذا البحث تم بداية استخدام الأسلوب المسحي لتحديد أنماط المناخ الأخلاقي السائدة في جامعة الملك عبد العزيز، وكذا لهندا 
من مجتمع الدراسة، وتم اختيارهم من المجموعة

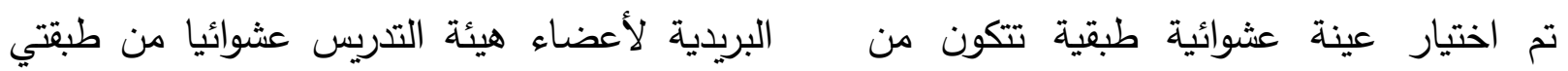
الدراسة وفق حجم كل طبقة في مجتمع الدراسة طبقتين (ذكور، وإناث)، تمثلان ما نسبته

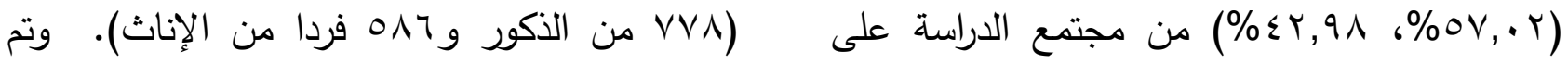
التوالي. وتم حساب حجم العينة وفق معادلة ستيفن إرسال مقياسي الدراسة عبر مسح اليكتروني عبر ثومبسون حيث بلغت (rع م مفردة) تمثل ما نسبته الويب web-based survey. وقد استجاب منهم

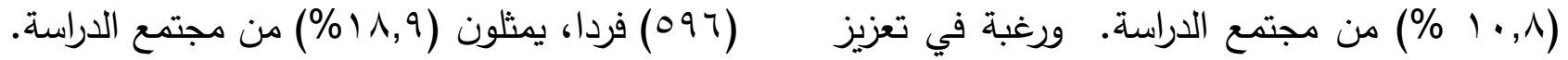

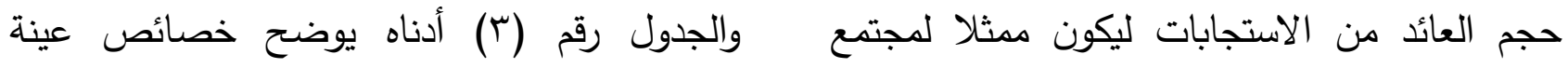
الدراسة بشكل صحيح، استهدف الباحث أربعة الدراسة:

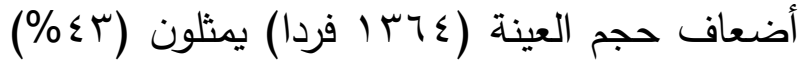

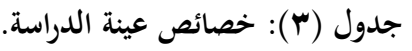

\begin{tabular}{|c|c|c|c|}
\hline النسبة (\%) & التكرار & الفئات & المتفير \\
\hline 50.3 & 300 & 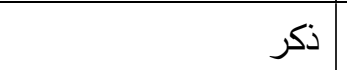 & \multirow[t]{2}{*}{ النوع } \\
\hline 49.7 & 296 & | أنثى & \\
\hline 41.9 & 250 & أقل من • ـ سنوات & \multirow[t]{3}{*}{ سنوات الخدمة } \\
\hline 31.2 & 186 & • 1 - أقل من ·r سنة & \\
\hline 26.8 & 160 & . . r سنة فأكثر & \\
\hline 17.4 & 104 & | أستاذ & \multirow[t]{4}{*}{ الرتبة العلمية } \\
\hline 18.8 & 112 & أستاذ مشارك & \\
\hline 39.3 & 234 & أستاذ مساعد & \\
\hline 24.5 & 146 & محاضر ، مدرس، معيد & \\
\hline$\% 1 \ldots$ & 097 & المجموع & \\
\hline
\end{tabular}

المقياس من (YT) فقرة تتوزع على خمسة أنماط: أداتي الاراسة:

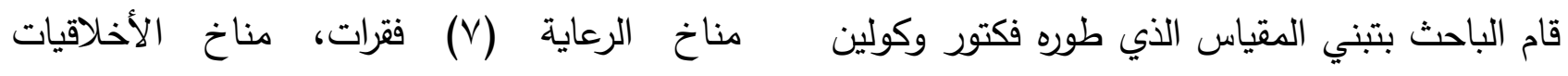
(Victor and Cullen, 1988)

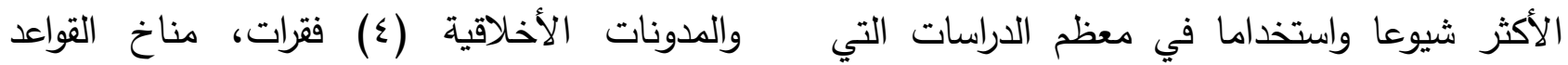

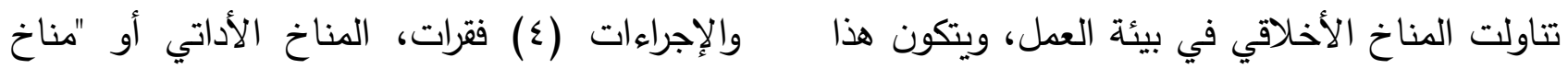


الوسائل"، وجميعها دالة إحصائياً عند مستوى دلالة

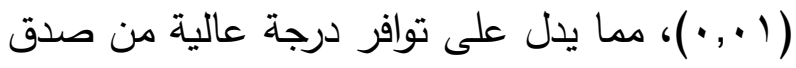

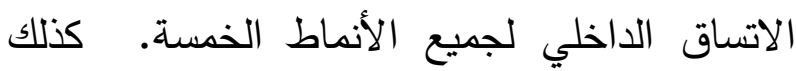
تتمتع هذه الأنماط الخمسة بدرجة ثبات عالية حيث المبان

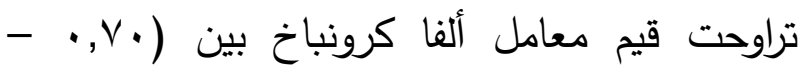
90 , • ) للأنماط الخمسة؛ وتثير قيم معاملات الثبات هذه إلى صلاحية المقياس للتطبيق والاعتماد على

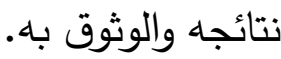
ثانيا: مقياس التماثل التنظيمي أظهر معامل ارتباط بيرسون قيم ارتباط عالية بين العبارات والدرجة الكلية لكل بعد من أبعاد التماثل

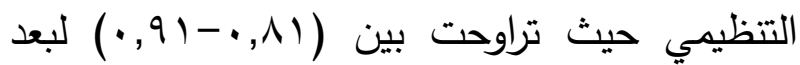

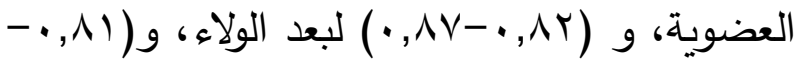

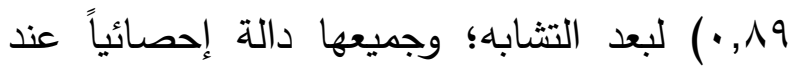
مستوى دلالة (1.,.•)، مما يدل على توافر درجة

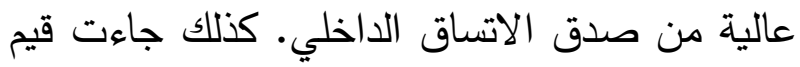
الارتباط بين الأبعاد الثلاثة سالفة الذكر والدرجة

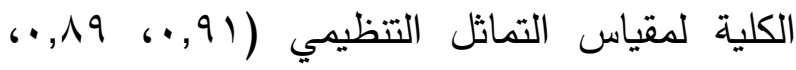
Vo, · • ) على التوالي، كما تراوحت قيم الارتباط بين عبارات المقياس والدرجة الكلية لمقياس بين

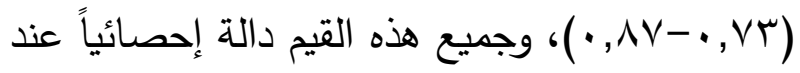
مستوى دلالة (1.,.•)، مما يدل على توافر درجة عالية من صدق الاتساق الداخلي للمقياس إجمالاً.

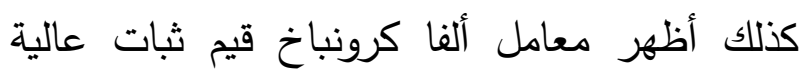
للأبعاد الثلاثة لمقياس التماثل التتظيمي حيث جاءت
الوسائل" (V) فقرات. ويتبع هذا المقياس تدرجاً يتكون من سبعة تقديرات (غير موافق بثدة -موافق بشدة). وقد استخدم هذا المقياس في العديد من

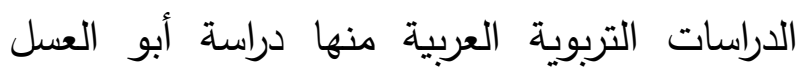

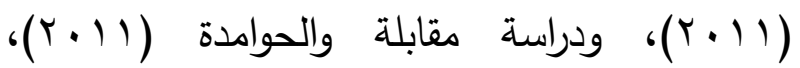
ودراسة الخزاعلة (ع ا • ب)، ودراسة الشريفي وآخرون (r. $(r)$ وفيما يتعلق بالتماثل التظيمي، استخدم مقياس طوره ميلر وآخرون (Miller et al, 2000) بالاستناد إلى بلى مقياس تثيني (Cheney,1983) للتماثل التظيمي Organizational Identification Questionnaire(OIQ) Translation and طريقة الترجمة وإعادة الترجمة Back Translation

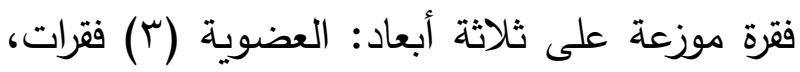

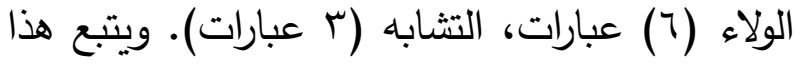
المقياس تدرجاً يتكون من سبعة تقديرات (غير موافق بشدة -موافق بثدة). صدق أداتي الدراسة وثباتهما: أولاً: مقياس المناخ الأخلاقي أظهرت معامل ارتباط بيرسون درجات ارتباط عالية بين العبارات والدرجة الكلية لكل نمط من الأنماط

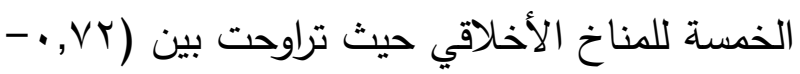

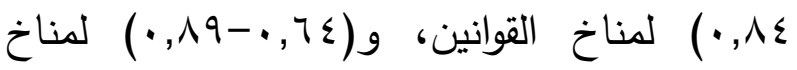

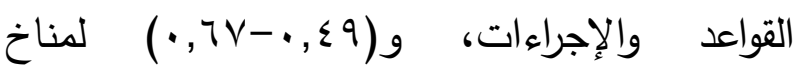

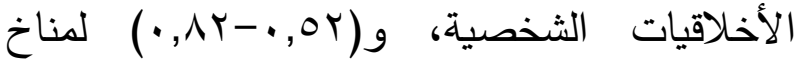

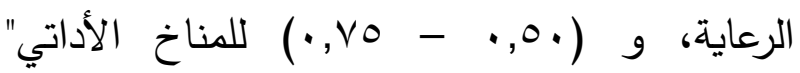




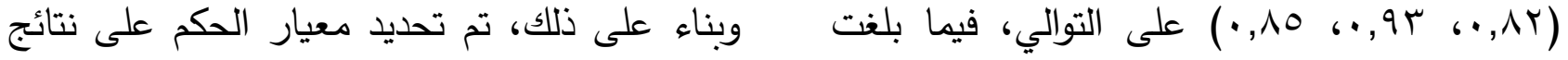

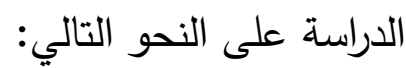

قيمة الثبات للمقياس إجمالا (90, • ·).

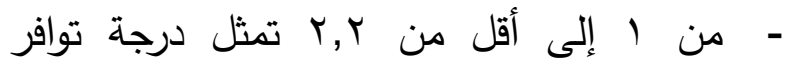

$$
\text { (متدنية جداً). }
$$

نتائج الدراسة:

- - من r, إلى أقل من ع,r تمثل درجة توافر

نظرا لكون المقاييس المستخدمة متدرجة على نحو

سباعي، ولتسهيل قراءة النتائج وتفسيرها تم تحويلها

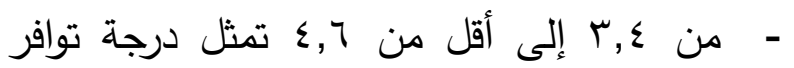
إلى خمسة تقديرات لفظية على النحو التالي: (متوسطة). طول الفئة = (l-V

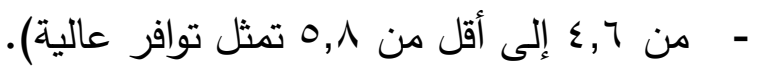

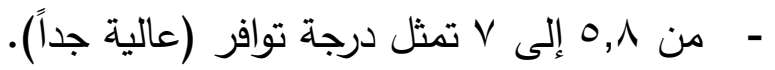

جدول رقم (؛): المتوسطات الحسابية والانحرافات المعيارية لاستجابات أعضاء هيئة التدريس

حول المناخ الأخلاقي السائد بالجامعة الإنهابه

\begin{tabular}{|c|c|c|c|c|c|}
\hline درجة التوافر & الترتيب & الانراف المعياري & المتوسط الحسابي & النمط & رقم البعد \\
\hline عالية & 1 & 1.26 & 5.004 & مناخ القوانين & 1 \\
\hline عالية & r & 1.35 & 4.72 & مناخ القواعد والإجراءات & r \\
\hline متوسطة & $r$ & 1.25 & 4.58 & مناخ الرعاية & $r$ \\
\hline متوسطة & $\varepsilon$ & 0.763 & 4.46 & المناخ الأداتي (الوسائل) & $\varepsilon$ \\
\hline متوسطة & 0 & .978 & 4.44 & مناخ الأخلاقيات الشخصية & 0 \\
\hline درجة التوافر & ترتيب & الانحراف المعياري & المتوسط الحسابي & البعد & رقم البعد \\
\hline عالية جدا & 1 & 1.21 & 5.87 & العضوية & 1 \\
\hline عالية & r & 1.46 & 5.24 & التشابه & $r$ \\
\hline عالية & r & 1.49 & 5.23 & الولاء & $r$ \\
\hline \multicolumn{2}{|l|}{ عالية } & 1.34 & 5.39 & \multicolumn{2}{|c|}{ التماثل التنظيمي إجمالا } \\
\hline
\end{tabular}

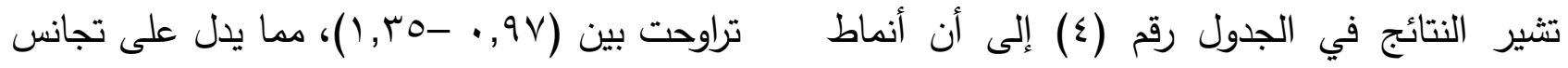

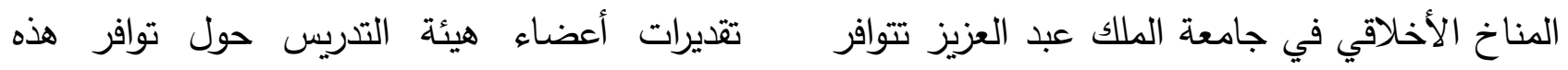
بدرجات متقاربة تراوحت بين (متوسطة، وعالية) من الأنماط الخمسة خصوصا فئرات إذا ما علمنا أن المقياس وجهة نظر أعضاء هيئة التدريس. كما يظهر من ذو تدرجه سباعي.

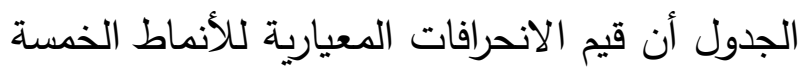


الأنانيـة في مقدمـة المناخـات الأخلاقيـة في بعض البيئات الجامعية.

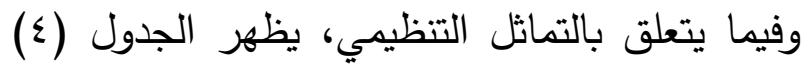
أن أعضاء هيئة التدريس يرون أنهم يتماثلون تنظيميا

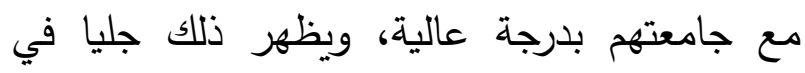
الأبعاد الثلاثة (العضوية، التشابه، الولاء) والتي لئي

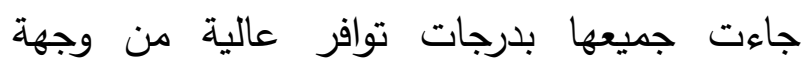
نظرهم. كذلك تراوحت قيم الانحرافات المعيارية

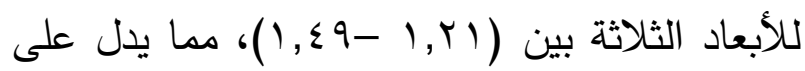

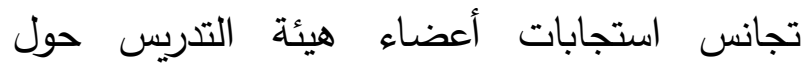
تقديرهم لتوافرها لديهم. وربما تعود الدرجة العالية للتماثل التتظيمي لدى أعضاء التدريس إلى كونهم

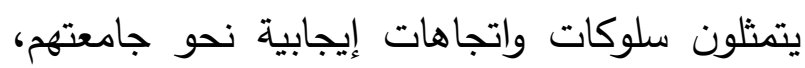
ويفتخرون بالانتساب والانتماء لجامعة عريقة بحجم الهات التهات

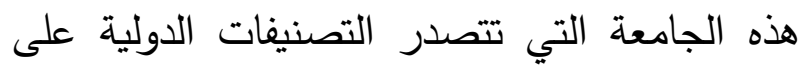

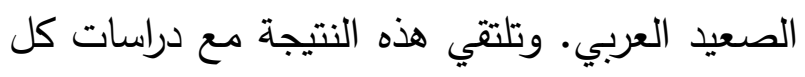

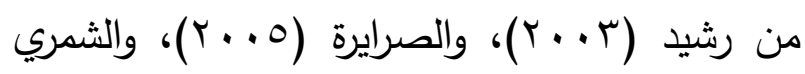

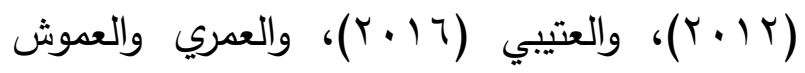
والتي أظهرت جميعها مستويات عالية من (Y C IV)

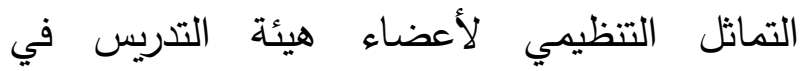

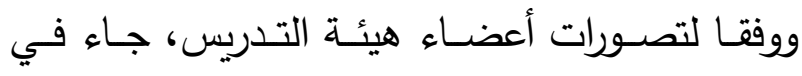
الترتيب الأول (منـاخ القوانين) بدرجـة توافر عاليـة،

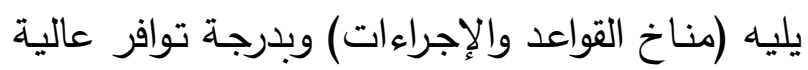

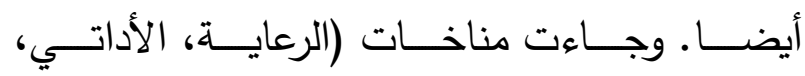

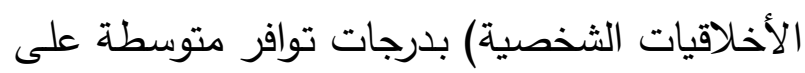

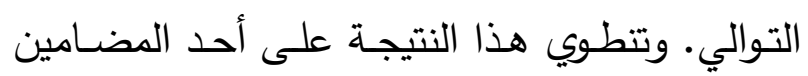
المهمة في أدبيات المناخ الأخلاقي وهي أن أشكال

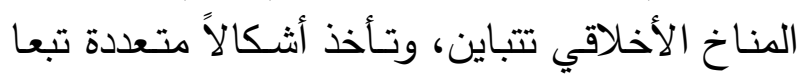

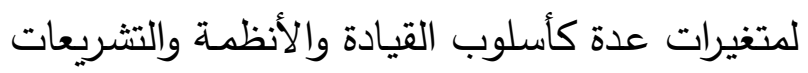
الحاكمة، ونوعية العلاقات في بيئة العمل (الثريفي

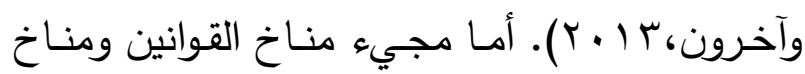
القواعد في صدارة ترتيب أنماط المناخ الأخلاقي في مني

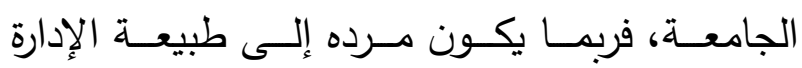
المركزيـة التي تهيمن على مجمل العمليات الإداريـة

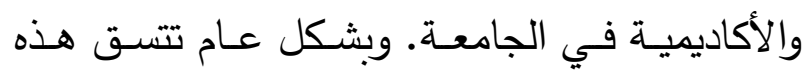

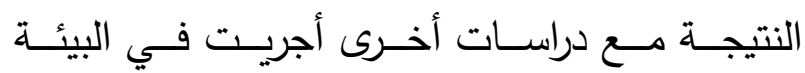

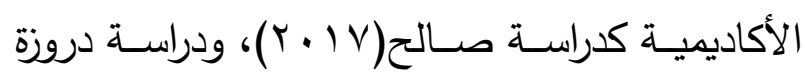

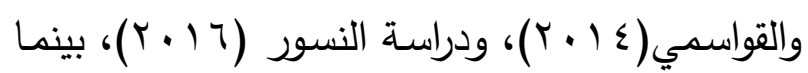
تختلف هذه النتيجة مع دراسة (Yl-Omari, 2013) و (Moore,2012) في ظهور المناخات ذات الصفة درات (A)

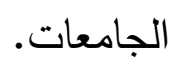
جدول رقم (•): نتائج اختبار بيرسون للعلاقة بين أنماط المناخ الأخلاقي والتماثل التنظيمي لأعضاء هيئة التدريس

\begin{tabular}{|c|c|}
\hline معامل الارتباط بالتماثل التتظيمي & أنماط المناخ الأخلاقي \\
\hline. $.61^{* * *}$ & مناخ القوانين \\
\hline$\cdot .60^{* * *}$ & مناخ القواعد والإجراءات \\
\hline. $.71^{* *}$ & مناخ الرعاية \\
\hline$\cdot .19^{* *}$ & (المناخ الأداتي (الوسائل) \\
\hline $0.144^{* *}$ & مناخ الأخلاقيات الشخصية (الاستقلالية) \\
\hline
\end{tabular}

** دال إحصائياً عند (1., (•) 
والتوحد مع جامعتهم، والانتماء إليها والثعور بانها

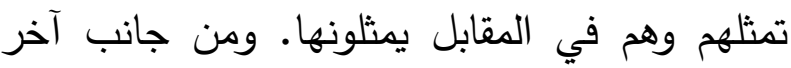
يظهر الجدول السابق أن (المناخ الأداتي " الوسائل")

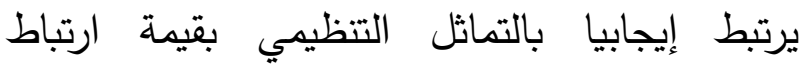
ضعيفة جذا (9 (,·). وهذا يعود إلى كون هذا المناخ يؤكد على تحقيق المنفعة الذاتية للجامعة على حساب الأمور الأخرى التي تتصل بأعضاء هيئة التدريس. وعلى النقيض جاء مناخ (الأخلاقيات الثخصية "الاستقلالية") مرتبطا بشكل سلبي بالتماثل

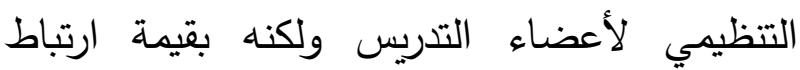
ضعيفة جدا (-ء (, •) وهذا يشير إلى أن التماتل التنظيمي لا يتأثر بالأخلاقيات والمبادئ الثخصية بقدر ما يتأثر بالعوامل التتظيمية كما ذكرنا آنفا. ومن هنا نلاحظ تباين حجم وقوة العلاقة بين أنماط المناخ الأخلاقي المختلفة والتماثل التتظيمي لأعضاء هيئة التدريس، وهذا ينسجم مع دراسة النسور

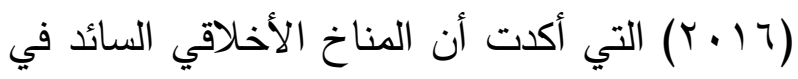
أي منظمة تعليمية له انعكاسات واضحة على اله سلوكات أعضاء المنظمة وأدائهم لأعمالهم، بل لبعاه ويعمل على تثكيل سلوكيات العاملين فيها. وعلى نحو مشابه، تتسجم هذه النتيجة مع دراستي موور وموور (Moore \& Moore, 2014)، وكنلك دراسة بوترانتا (Putranta,2008) واللتين توصلتا إلى وجود اختلافات في مستويات الالتزام التنظيمي في
يتضح من الجدول (0) أن معامل ارتباط مناخ الرعاية بالتماثل التنظيمي لدى أعضاء هيئة التدريس

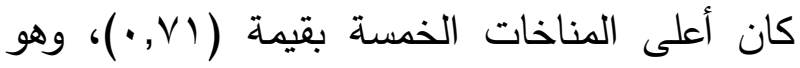
ارتباط طردي (عال) ودال إحصائياً عند مستوى لعالري ( ( , •)، وهذا يشير إلى أنه كلما كان مناخ الرعاية سائدا في الجامعة، كان ذلك أدعى لزيادة كبيرة في مستوى التماثل التظظيمي لاى أعضاء هيئة التدري؛ لهي؛ وهذا ربما يكون مرده إلى أن أعضاء هيئة التدريس يشعرون بالتقدير والاهتمام بمصالحهم في مثل هذا المناخ الذي يحقق لهم السعادة التنظيمية ويوفر لهم

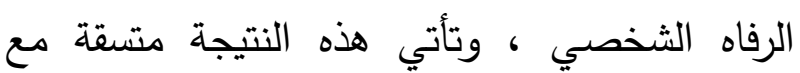
Cullen et al., 2003; Victor \& Cullen, ) دراستي 1988) التي توصلت إلى أن مناخ الخيرية والرعاية يعزز السلوكات الإيجابية مثل الالتزام التتظيمي. وعلى نحو مشابه جاء (مناخ القوانين، مناخ القواعد والإجراءات) بقيم ارتباط عالية أيضا بالتماثل التنظيمي لأعضاء هيئة التدريس (الآ, •، • •T, •)، وكلاهما دال إحصائياً عند مستوى (1 (.,.). وهذا لإنا يدل أن مثل هذا المناخات التي تركز على الامتثال للقانون والمعايير المهنية والالتزام بسياسات المنظمة وإجراءاتها تحفظ للجامعة هويتها، ووحدتها وتماسكها التنظيمي، وتحافظ على مكتسباتها المؤسسية، وتوفر بيئة تتسم بالعدالة التنظيمية يتساوى فيها الجميع في

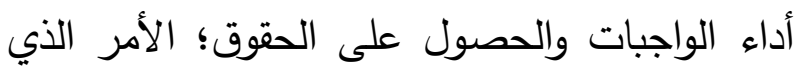
يجعل أعضاء هيئة التدريس يشعرون بالانسجام 
الجامعات تبعا لاختلاف أنماط المناخ الأخلاقي

جدول (†): تحليل الانحدار المتعدد لقدرة أنماط المناخ الأخلاقي في التنبؤ بالتماثل التظيمي لاى أعضاء هيئة التدريس

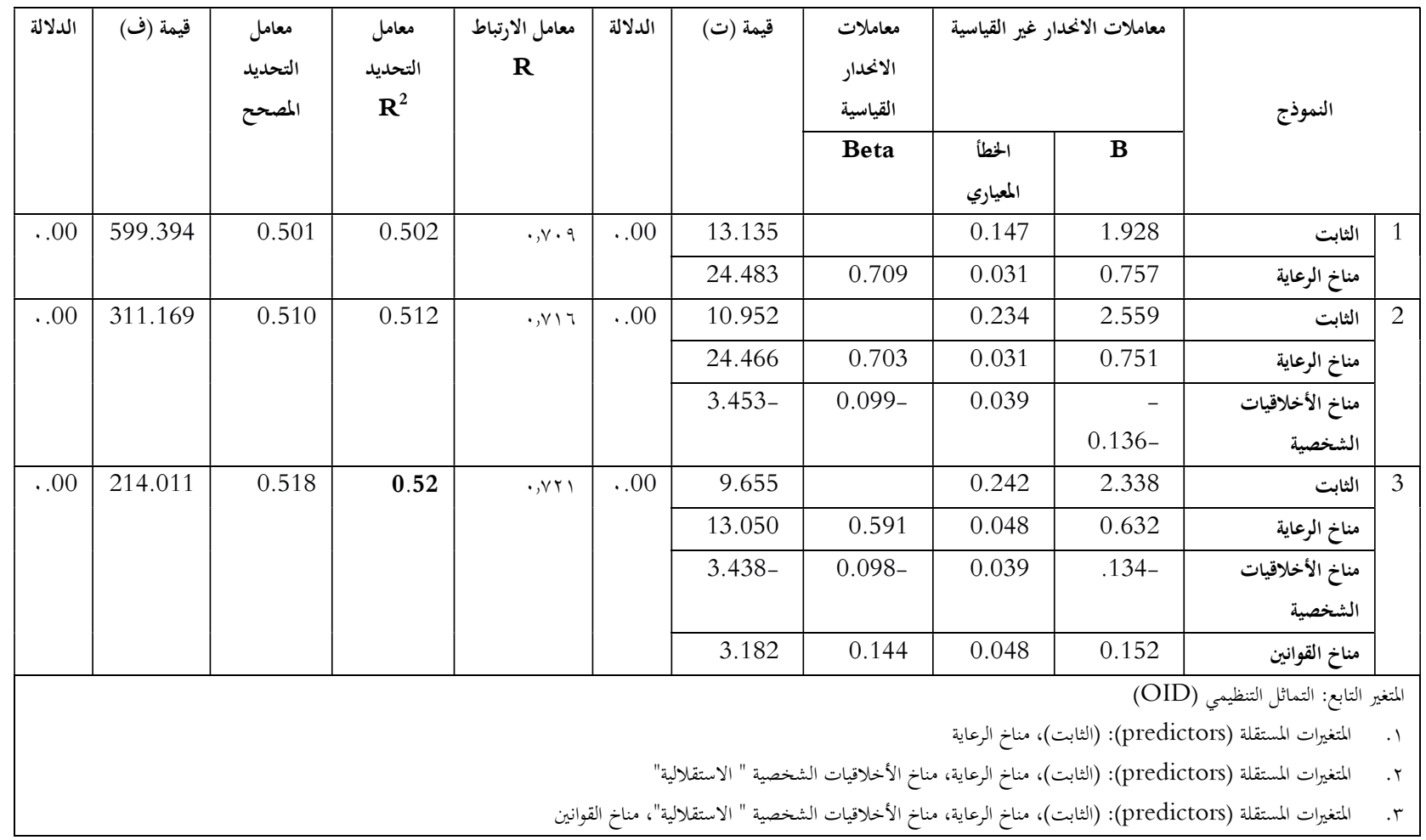

التتظيمي لاى أعضاء هيئة التدريس والذي يمكن أن

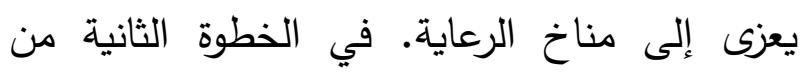

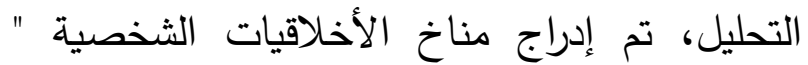
الاستقلالية" في معادلة الانحدار وكان الارتباط عندها كبيرا بالتماثل التنظيمي لدى أعضاء هيئة

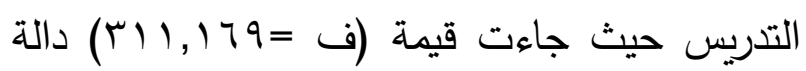
إحصائيا عند مستوى |+,.•، وجاء دعامل الارتباط

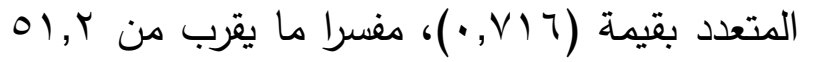

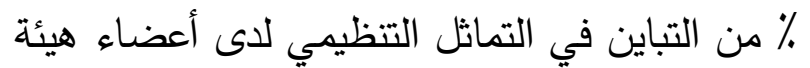
التدريس والذي يمكن أن يعزى إلى مناخ الرعاية
لتحديد قدرة أنماط المناخ الأخلاقي على تفسير التباين في التماثل التنظيمي لاى أعضاء هيئة التدري، أجري تحليل الانحدار المتعدد التدريجي

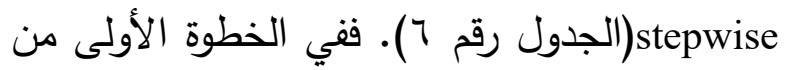
التحليل، تم إدراج مناخ الرعاية في معادلة الانحدار

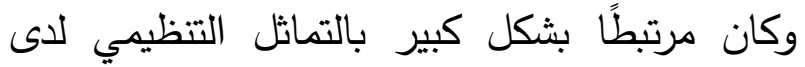
أعضاء هيئة التدريس حيث جاءت قيمة (ف بـ

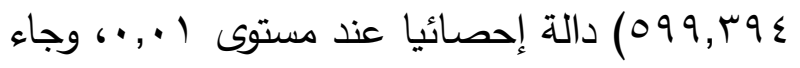

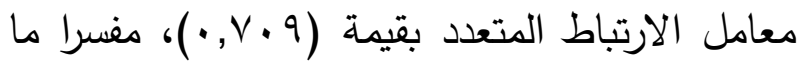
يقرب م من r, •• \% من التباين في التماثل 
ومن جهة أخرى لم تظهر أنماط المناخ الأخلاقي الأخرى كعوامل ذات دلالة إحصائية في لمري التنبؤ بالتماثل التنظيمي لدى أعضاء هيئة التدريس وتفسيره، ولذا تم استبعادها من التحليل. وبناءً على

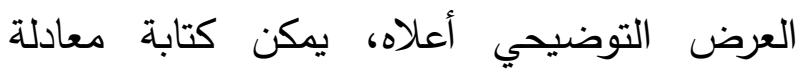
الانحدار كما يلي: التماتي: التماثل التظيمي لأعضاء هيئة التدريس

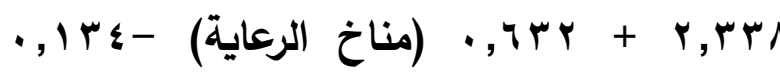

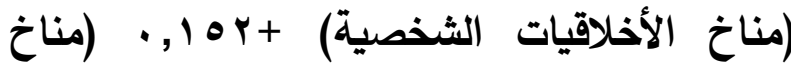
(القوانين)
ومناخ الأخلاقيات الثخصية معاً. في الخطوة الثالثة من التحليل، تم إدخال مناخ القوانين في معادلة الانحدار وكان الارتباط عندها كبيرا بالتماثل التنظيمي لدى أعضاء هيئة التدريس حيث جاءت الأدياء

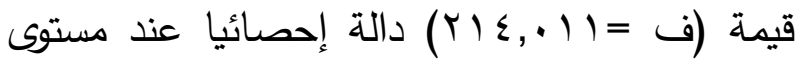
1.,.,، وجاء معامل الارتباط المتعدد بقيمة

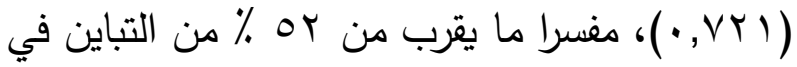

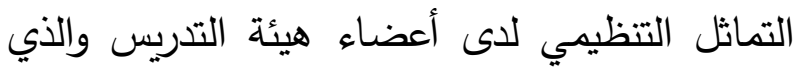

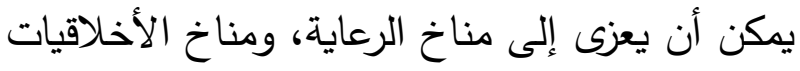
الشخصية، ومناخ القوانين مجتمعة. جدول رقم (V): نتائج اختبار (ت) لعينتين مستقلتين للتعرف على دلالة الفروق حول (أنماط المناخ الأخلاقي السائد في الجامعة، والتماثل التنظيمي لأعضاء هيئة التدريس) والتي تعزى لاختلاف النوع لالتهن

\begin{tabular}{|c|c|c|c|c|c|c|}
\hline مستوى الدلالة & ت ت ت ت ت & الانحراف المعياري & المتوسط الحسابي & 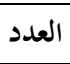 & النوع & المتغيرات \\
\hline \multirow[t]{2}{*}{ ***.*... } & \multirow[t]{2}{*}{$0, . r$} & 1.21723 & 4.8301 & r97 & ذكر & \multirow[t]{2}{*}{ مناخ الرعاية } \\
\hline & & 1.24210 & 4.3248 & $r .$. & أنتى & \\
\hline \multirow[t]{2}{*}{$\cdot, I V V$} & \multirow[t]{2}{*}{$1,0 \mathrm{rr}$} & .94885 & 4.3851 & r97 & ذكر & \multirow[t]{2}{*}{ مناخ الأخلاقيات الشخصية } \\
\hline & & 1.00540 & 4.4933 & r.. & أننى & \\
\hline \multirow[t]{2}{*}{ ***.,.. } & \multirow[t]{2}{*}{ r,o. } & 1.30615 & 5.1858 & r97 & ذكر & \multirow[t]{2}{*}{ مناخ القوانين } \\
\hline & & 1.20608 & 4.8250 & $r \ldots$ & أننى & \\
\hline \multirow[t]{2}{*}{ ***....1 } & \multirow[t]{2}{*}{ r, r } & 1.32183 & 4.9003 & r97 & ذكر & \multirow[t]{2}{*}{ مناخ القواعد والإجراءات } \\
\hline & & 1.35659 & 4.5350 & $r \ldots$ & أننى & \\
\hline \multirow[t]{2}{*}{$\cdot, \cdot \sqrt{ } 4$} & \multirow[t]{2}{*}{$1, \mathrm{VV}$} & .79170 & 4.4025 & r97 & ذكر & \multirow[b]{2}{*}{ المناخ الأداتي } \\
\hline & & .73153 & 4.5133 & $r .$. & أننى & \\
\hline \multirow[t]{2}{*}{ ***.,.. } & \multirow[t]{2}{*}{$0, \cdot v$} & 1.27885 & 5.6684 & r97 & ذكر & \multirow[t]{2}{*}{ التماثل التنظيمي } \\
\hline & & 1.34715 & 5.1222 & r.. & أننى & \\
\hline
\end{tabular}

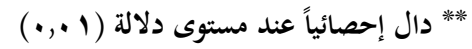
يتيسن من الجدول رقم (V) وجود فروق ذات دلالة لاختلاف النوع، حيث جاءت قيمة (ت) لـ (مناخ إحصائية بين متوسطات استجابات أعضاء هيئة الرعاية) بقيمة (r., (O) وهي دالة إحصائياً عند

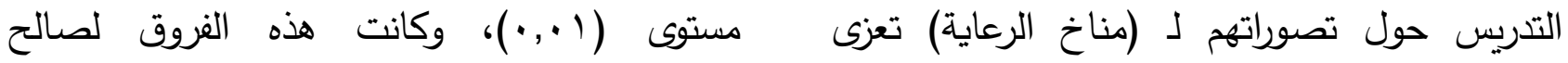


وعلى النقيض، يظهر الجدول رقم (V) عدم وجود فروق ذات دلالة إحصائية بين متوسطات استجابات أعضاء هيئة التدريس حول تصوراتهم لنمطي (مناخ

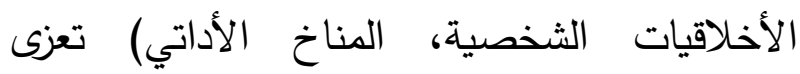
لاختلاف النوع، حيث جاءت قيمتي (ت) لهذين

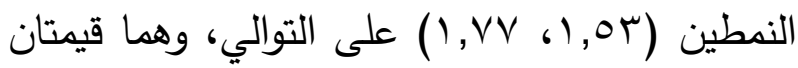
غير دالتين إحصائياً عند مستوى (0. . •).)

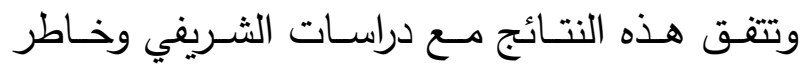

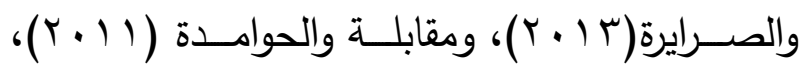

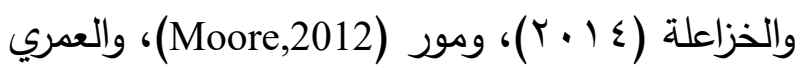

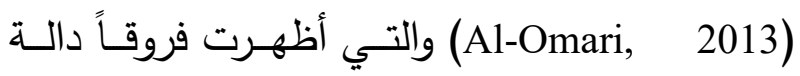
إحصـائيا حـول المنـاخ الأخلاقي بـاختلاف متغيـر

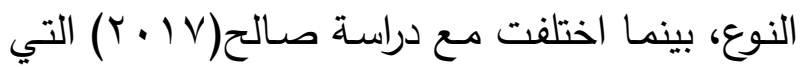
أظهرت عدم وجود فروق ذات دلالة إحصائية حول المناخ الأخلاقي تبعاً لاختلاف النوع.

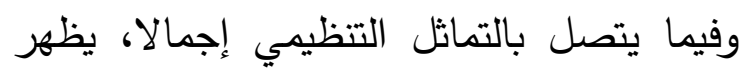
الجدول رقم (V) وجود فروق ذات دلالة إحصائية

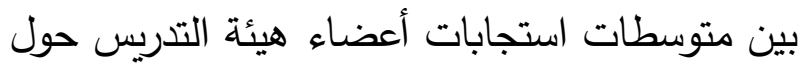
تقديراتهم لمستوى تماتلهم تتظيميا مع جامعتهم تبعاً لاختلاف النوع، حيث جاءت (ت) بقيمة (v, (0)، وهي قيمة دالة إحصائيا عند مستوى (1 (.,·)، وكانت هذه الفروق لصالح (الذكور). وقد يعود هذا إلى وجود اختلافات في بيئة العمل حيث يحظى شطر الطلاب بمزايا أفضل من حيث المباني، والمرافق المختلفة، والتجهيزات والتسهيلات التي لتهريات تتصل بها، كذلك ربما ترى الإناث أن أعضاء
(الذكور).وربما يكون مرد ذلك إلى أن البيئة التي يعمل فيها أعضاء هيئة التدريس في شطر الطالبات لا تتماثل من حيث تجهيزاتها ومرافقها مع البيئة التي لئي

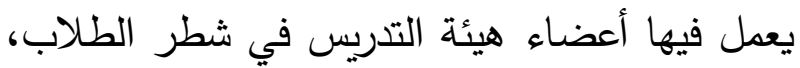
وقد يعود ذلك إلى حرص أعضاء هيئة التدريس الذكور على الحفاظ على مصالح بعضهم البعض إلى في الجامعة بدرجة أكبر من الإناث. كما يتبين من الجدول رقم (V) وجود فروق ذات الات لعن دلالة إحصائية بين متوسطات استجابات أعضاء هيئة التدريس حول تصوراتهم لنمطي (مناخ القوانين،

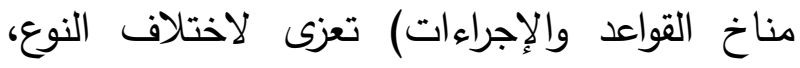
حيث جاءت قيمة (ت) لهذين المناخين (ب,0ب، rr,r, على التوالي، وكلتاهما دالتان إحصائياً عند مستوى (1.,·)، وكانت هذه الفروق لصالح (الذكور). وربما يعود ذلك إلى أن أعضاء التدريس من الإناث يرين أن القوانين والمواثيق الأخلاقية وكذا لفاء الفاء القواعد والإجراءات التظيمية المعمول بها في الجامعة لا تزال غير منصفة لهم مقارنة بالذكور، واللذين ربما يحظون بمزايا وحوافز أكثر منهن كعضوية اللجان التنفيذية، واللجان الدائمة، ولجان المجلس العلمي، ومجلس الجامعة. أو قد يكون ذلك بسبب أن هذه القوانين والقواعد الإجرائية لا تطبق على النحو الأمثل في شطر الطالبات لأسباب كثيرة قد يكون منها أسلوب القيادة، وتعدد جهات الإشراف على شطر الطالبات، وتنازع الصلاحيات. 
التدريس في شطر الطلاب يحظون بحوافز أكثر هذه النتيجة مختلفة مع دراستي العمري والعموش

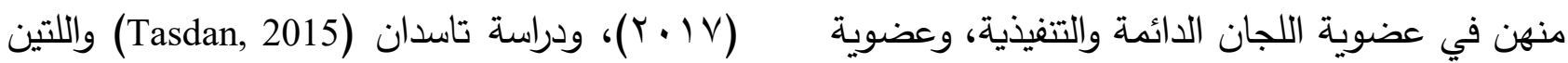
المجلس العلمي، ومجلس الجامعة؛ الأمر الذي لم تلتوصلا إلى أيه فروق دالة إحصائيا حول التماثل جعلهن يظهرن أقل تماثلا تتظيميا من الذكور • وتأتي التنظيمي باختلاف النوع. جدول رقم (^): اختبار تحليل التباين الأحادي للتعرف على دلالة الفروق حول (أنماط المناخ الأخلاقي السائد في الجامعة،

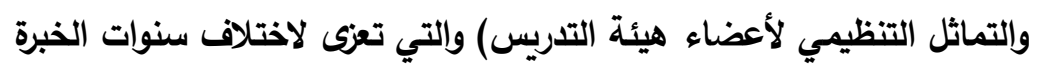

\begin{tabular}{|c|c|c|c|c|c|c|}
\hline الدلالة الإحصائية & ف & متوسط المربعات & درجات & مجموع المربعات & مصادر التباين & المتغيرات \\
\hline .043 & 3.154 & 4.928 & 2 & 9.857 & بين الجمموعات & \multirow{3}{*}{ مناخ الرعاية } \\
\hline & & 1.563 & 593 & 926.581 & داخل الجموعات & \\
\hline & & & 595 & 936.438 & الكلي & \\
\hline \multirow{3}{*}{.244} & 1.414 & 1.352 & 2 & 2.704 & بين الجمموعات & \multirow{3}{*}{ مناخ الأخلاقيات الشخصية } \\
\hline & & .956 & 593 & 566.871 & داخل الجموعات & \\
\hline & & & 595 & 569.576 & الكلي & \\
\hline \multirow[t]{3}{*}{.024} & 3.757 & 5.991 & 2 & 11.981 & بين الجمموعات & \multirow{3}{*}{ مناخ القوانين } \\
\hline & & 1.595 & 593 & 945.633 & داخل الجموعات & \\
\hline & & & 595 & 957.615 & الكلي & \\
\hline \multirow[t]{3}{*}{.023} & 3.801 & 6.871 & 2 & 13.741 & بين الجموعات & \multirow[t]{3}{*}{ مناخ القواعد والإجراءات } \\
\hline & & 1.807 & 593 & 1071.837 & داخل الجموعات & \\
\hline & & & 595 & 1085.579 & الكلي & \\
\hline \multirow[t]{3}{*}{.018} & 4.067 & 2.346 & 2 & 4.691 & بين الجموعات & \multirow{3}{*}{ المناخ الأداتي (الوسائل) } \\
\hline & & 4.928 & 593 & 342.047 & داخل الجموعات & \\
\hline & & 1.563 & 595 & 346.739 & الكلي & \\
\hline \multirow[t]{3}{*}{.033} & 3.434 & & 2 & 12.246 & بين الجمموعات & \multirow[t]{3}{*}{ التماثل التنظيمي } \\
\hline & & 1.352 & 593 & 1057.280 & داخل الجموعات & \\
\hline & & .956 & 595 & 1069.526 & الكلي & \\
\hline
\end{tabular}

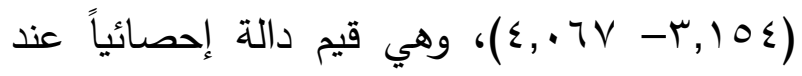
مستوى الدلالة (0. (·) (·).

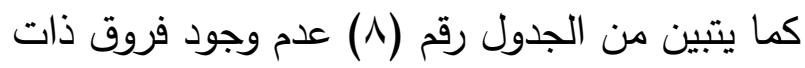
دلالة إحصائية بين متوسطات استجابات أعضاء هيئة التدريس حول تصوراتهم لـناخ (الأخلاقيات الثخصية) تعزى لاختلاف سنوات الخبرة، حيث لاندون
يتبين من الجدول رقم (^) وجود فروق ذات دلالة إحصائية بين متوسطات استجابات أعضاء هيئة التدريس حول تصوراتهم لمناخات (الرعاية، القوانين،

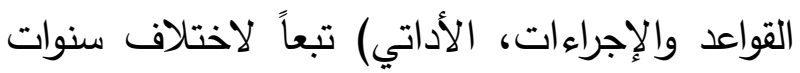

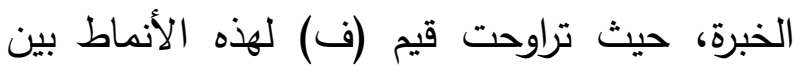


توقعاتهم، وتحقق لهم الرفاه الثخصسي من جانب،

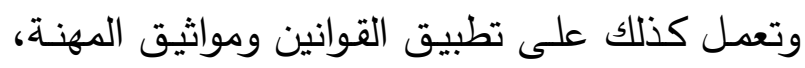
والقواعد والإجراءات على النحو الذي يحقق الفاعلية التنظيمية والتعليمية. وتلتقي هذه النتيجة مـع دراسات

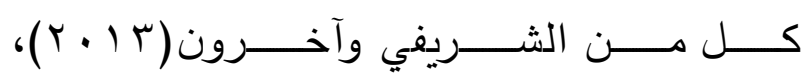

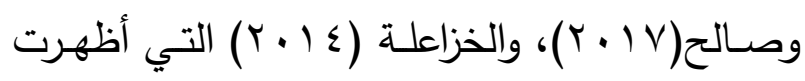

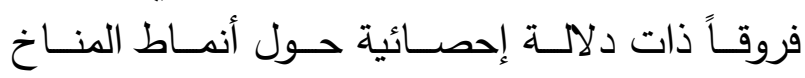

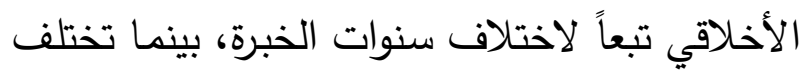

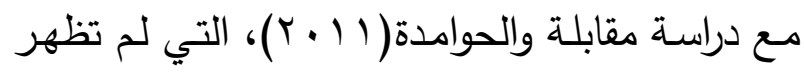

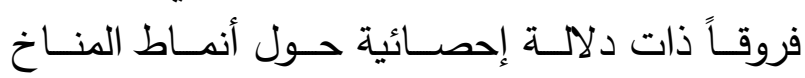
الأخلاقي تعزى لاختلاف سنوات الخبرة.

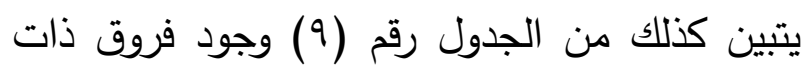

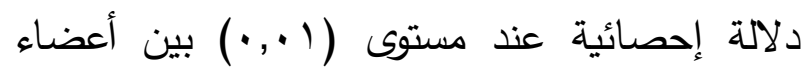

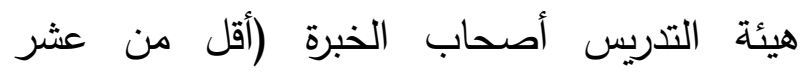

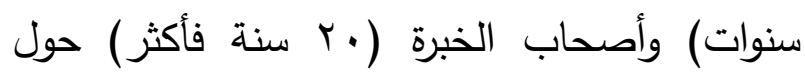

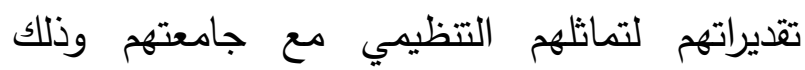

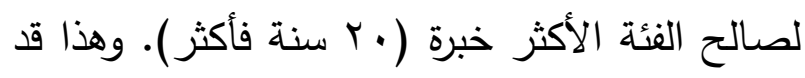

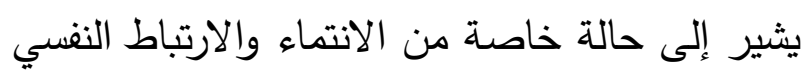

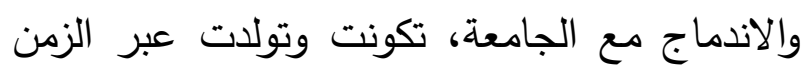

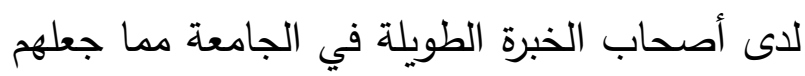
يظهرون تقديرات أعلى لحالة التماثل التنظيمي لديهم. وتتفق هذه النتيجة مع دراسة رشيد(ب . . ب) التي أفادت بأن مستوى تماثل عضو هيئة التدريس

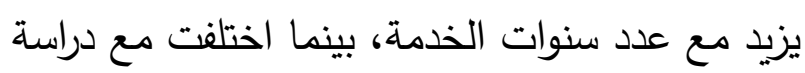

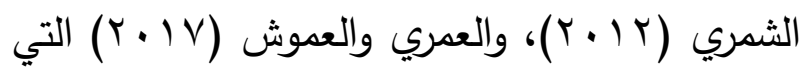
لم تظهر فروقا دالة احصائياً حول التماثل التنظيمي باختلاف سنوات الخبرة.
بلغت قيمة (ف) لهذا المناخ (ع (ع, ())، وهي قيمة غير دالة إحصائياً عند مستوى دلالة (ه •., •). وربما

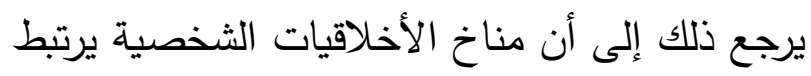
بالمبادئ والقيم والمعتقدات الذاتية لأعضاء التدريس

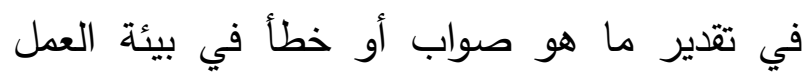
بصرف النظر عن سنوات خبرتهم في العمل في في الأكاديمي. كذلك يتبين من الجدول رقم (^) وجود فروق ذات دلالة إحصائية بين متوسطات استجابات أعضاء

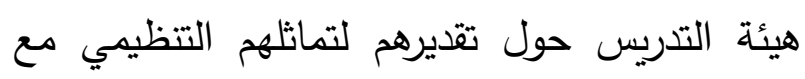

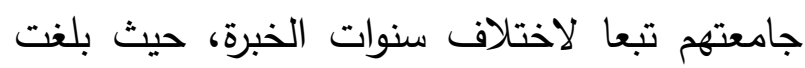

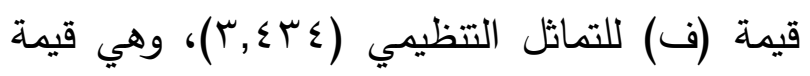
دالة إحصائياً عند مستوى الدلالة (0. •. •).

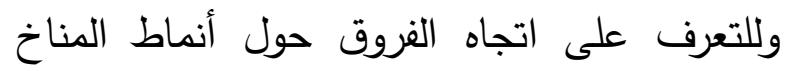
الأخلاقي في الجامعة وكذلك التماثل التنظيمي الجاه التياء لأعضاء هيئة التدري، أجري اختبار

البعدي كما في الجدول رقم (9).

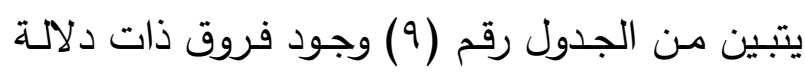

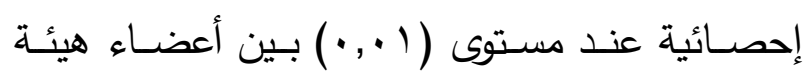
التدريس أصحاب الخبرة (أقل من عشر سنوات، ، ل

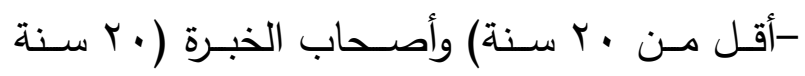
فأكثر) حول تصوراتهم لمناخات (الرعاية، القوانين،

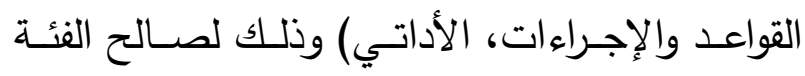

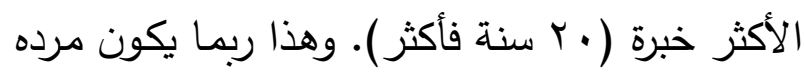

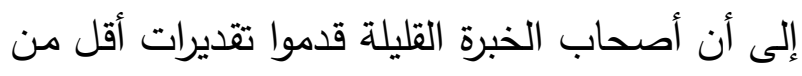

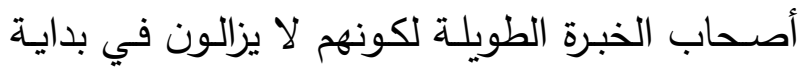
العمل الأكاديمي ويتطلعون ويطمحون إلى مناخات أخلاقية تميل إلى المثالية، تراعي مصـالحهم وتلبي 
جدول رقم (9): نتائج اختبار LSD للمقارنات البعدية لتحديد اتجاه الفروق حول (أنماط المناخ الأخلاقي في الجامعة، والتماثل

\begin{tabular}{|c|c|c|c|c|c|c|}
\hline r r سنة فأكثر & 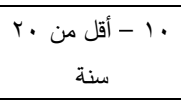 & سنو من · 1 أقل & المتوسط الحسابي & 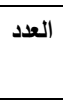 & سنوات الذدمة في الجامعة & المتغير \\
\hline & & --- & $\varepsilon, T \wedge r$ & 250 & أقل من · ـ سنوات & \multirow{3}{*}{ مناخ الرعاية } \\
\hline & --- & & $\varepsilon, \Gamma q \leq \wedge$ & 186 & . 1 - أقل من ·r سنة & \\
\hline \multirow[t]{3}{*}{---} & $*, r r \leq \wedge V$ & & $\varepsilon, \vee 197$ & 160 & 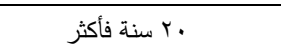 & \\
\hline & & --- & $\varepsilon, 9 \uparrow \ldots$ & 250 & أقل من · · سنوات & \multirow{3}{*}{ مناخ القوانين } \\
\hline & --- & & $\varepsilon, q \cdot r r$ & 186 & 1 - أقل من ·r سنة & \\
\hline \multirow[t]{3}{*}{---} & $*, r r \leq r V$ & $*, r \cdot v \theta$. & 0, rTVO & 160 & 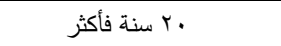 & \\
\hline & & --- & $\varepsilon, \uparrow \wedge \ldots$ & 250 & أقل من · ا سنوات & \multirow{3}{*}{ مناخ القواعد والإجراءات } \\
\hline & --- & & $\{, 0711$ & 186 & 1 - أقل من ·r سنة & \\
\hline \multirow[t]{3}{*}{---} & *.,rqाr. & *., YVUTIT & $\varepsilon, 9041$ & 160 & r r سنة فأكثر r . & \\
\hline & & $\begin{array}{ll}--- & \end{array}$ & $\varepsilon, \varepsilon \wedge 11$ & 250 & أقل من · ا سنوات & \multirow{3}{*}{ المناخ الأداتي (الوسائل) } \\
\hline & --- & & 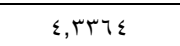 & 186 & 1 - أقل من ·r سنة & \\
\hline \multirow[t]{2}{*}{$\begin{array}{l}-- \\
--\end{array}$} & 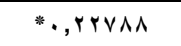 & & $\{, 07 \leqslant r$ & 160 & r r سنة فأكثر r. & \\
\hline & & --- & $0, r \vee \cdots$ & 250 & أقل من · · سنوات & \multirow[t]{3}{*}{ التماثل التنظيمي } \\
\hline \multirow[t]{2}{*}{---} & $\begin{array}{ll}-- & \\
-1\end{array}$ & & 0, & 186 & . - أقل من ·r سنة & \\
\hline & & *., & 0, гат० & 160 & . r سنة فأكثر. & \\
\hline
\end{tabular}

\section{التنظيمي لأعضاء هيئة التدريس) باختلاف سنوات الخبرة}

خلاصة النتائج والتوصيات:

مفسرا لوحده ما يقرب من r, •• \% من التباين في التماثل التظيمي للى أعضاء هيئة التدري. ومن جانب آخر، تبين وجود فروق دالة إحصائيا بين متوسطات استجابات أعضاء هيئة التدريس حول مناخات (الرعاية، القوانين، القواعد والإجراءات) تعزى لاختلاف النوع ولصالح (الذكور)؛ وجود فروق دالة إحصائيا أعضاء هيئة التدري حول تقديراتهم لتماثلهم تتظيميا مع جامعتهم تعزى لاختلاف النوع ولصالح (الذكور)؛ ووجود فروق دالة إحصائيا بين أعضاء هيئة التدريس حول تصوراته لمناخات (الرعاية، القوانين، القواعد والإجراءات، الأداتي) تبعاً لاختلاف سنوات خبرتهم ولصالح أصحاب الخبرة
خلصت الدراسة إلى تعدد أنماط المناخ الأخلاقي في الجامعة وكان في مقدمتها (مناخ القوانين، مناخ القواعد والإجراءات) بلدرجات توافر عالية، فيما توافرت مناخات (الرعاية، والأخلاقيات الثخصية، والمناخ الأداتي) بدرجات متوسطة. ومما توصلت إليه الدراسة ارتفاع درجة التماثل التتظيمي للى أعضاء هيئة التدري إجمالا وفي أبعاده الثلاثة أيضا. كما تبين وجود علاقة ارتباطية طردية دالة إحصائيا عند مستوى (1, (., ) بين مناخات (القوانين، القواعد والإجراءات، الرعاية) والتماثل التظيمي لدى أعضاء هيئة التدري. وجاء معامل الارتباط المتعدد لمناخ الرعاية بقيمة (9. V,•)؛ 
السلوك الأخلاقي الرفيع، ومعالجة الانحرافات عن السلوكات المتوقعة في الجامعة. • إجراء مسوحات دورية ومقابلات مقننة ورصينة لتحديد المناخات السائدة في الكليات والمعاهد والإدارات المختلفة قبل تنفيذ الاستراتيجيات والتدخلات التي تعزز التماثل التظيمي لأعضاء هيئة التدريس لكون المناخات المختلفة تتطلب لهرب لاتبات

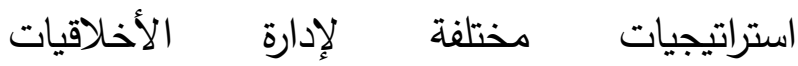

.(Deshpande, George, \& Joseph, 2000) • معالجة الجوانب السلبية للمناخ الأداتي من خلا اتخاذ الإجراءات اللازمة التي تكفل إيجاد موازنة مصلحيه تحقق منافع أو مصالح أعضاء هيئة التدريس وكذلك مصلحة الجامعة في المقام الأول مع تقديم المصالح والمكاسب المؤسسية للجامعة في حال تعارضها مع الجوانب النفعية لأعضاء هيئة

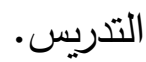

\section{مجالات البحث المستقبلية:}

نظرا لكون هذه الدراسة ذات منهجية مسحية ارتباطية في طبيعتها، ربما يكون من الأجدر إجراء دراسات نوعية وأخرى مزجية لتقصي المناخات الأخلاقية، والتماثل التنظيمي بثكل دقيق. كذلك من المهم جدا

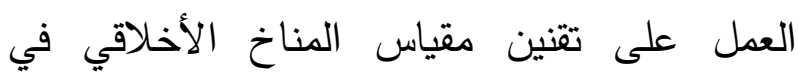
السياق العربي باستخدام اختبارات التصميم العاملي، لتيسير استخدامه في إجراء دراسات للتتبؤ بسلوكات العاملين الأخرى في بيئة العمل. وعلى صعيد دراسات المناخ الأخلاقي في الجامعات، يمكن إجراء
الطويلة؛ ووجود فروق دالة إحصائيا بين أعضاء هيئة التدريس حول تقديرهم لتماتلهم التتظيمي مع جامعتهم تبعا لاختلاف سنوات خبرتهم ولصالح أصحاب الخبرة الطويلة. وفي ضوء هذه النتائج تقدم

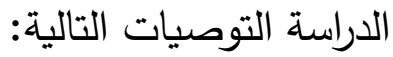
• توجيه أنظار القيادات الأكاديمية في الجامعة إلى اتخاذ التصرفات والتدابير اللازمة لتنمية مناخ الخيرية والرعاية باستخدام الاتصالات المفتوحة، والقيادة التثاركية، وتحسين جودة الحياة الوظيفية، وتتمية العمل الجماعي، وتعزيز المسؤلية الاجتماعية والاهتمام بالصالح العام، لما لذلك من نتائج تثغيلية إيجابية في رفع مستوى التماثل التتظيمي لأعضاء هيئة التدريس إلى جانب زيادة الإنتاجية، وزيادة الإبداع، وانخفاض الدوران الوظيفي، وانحسار سلوكيات العمل غير المقبولة. • إعادة صياغة القوانين واللوائح والقواعد والإجراءات التنظيمية لتكون أكثر مرونة لكي تسهح في خلق بيئة عمل تعاونية تؤدي إلى التكامل في تحقيق المصالح المشتركة للجامعة وأعضاء هيئة التدريس دون إخلال بالقوانين واللوائح. تعزيز مناخ القوانين من خلال بناء مدونات أخلاقية حديثة للعمل الجامعي تكون لها صفة لهات لهات

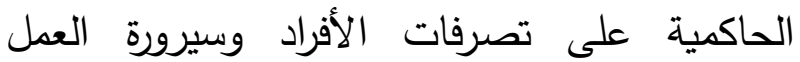
الإداري والأكاديمي على حد سواء على أن تتضمن الكيفية الإجرائية التي يتم من خلالها ترسيخ قواعد 


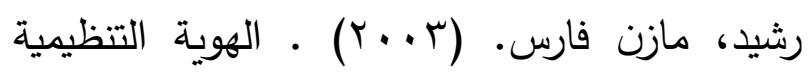
والتماثل التنظيمي: تحليل للمفهوم والأبعاد السلوكية فئن لتطبيقاته. مركز البحوث بكلية العلوم الادارية

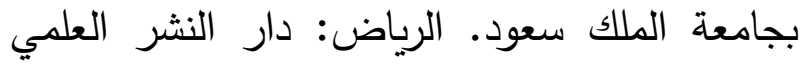
والمطابع. الزغلوان، معتصم ياسين. ( ع ( • ب). النمط القيادي

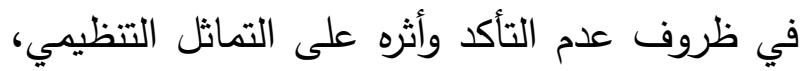

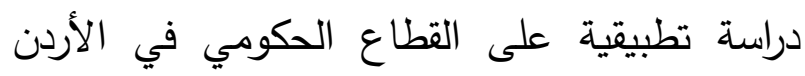

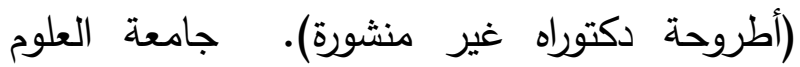
الاسلامية العالمية، عمان. الشريفي، عباس، والصرايرة، خالد، خاطر، أيمن.

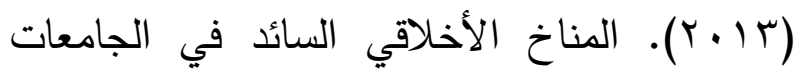
الأردنية من وجهة نظر العاملين فيها. مؤتة للبحوث

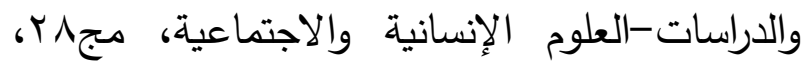
$.1 \% 0-90,4 \varepsilon$ الثمري، أحمد مطر • (Y (Y) ) • درجة ممارسة الأدوار القيادية لدى عمداء الكليات في جامعة الكويت وعلاقتها بالتماثل التنظيمي لدى أعضاء هيئة التدريس من وجهة نظرهم (رسالة ماجستير غير منشورة). كلية العلوم التربوية بجامعة الشرق الأوسط، عمان.

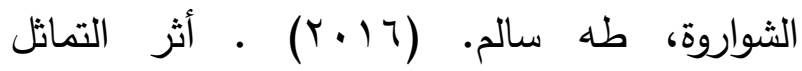
التنظيمي في دافعية العمل لدى معلمي وزارة التربية والتعليم الأردنية في مديرية التربية والتعليم لقصبة الكرك. مجلة الجامعة الإسلامية للدراسات

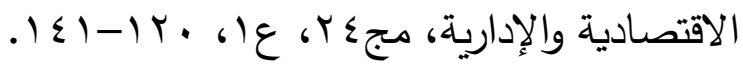

بحوث مستقبلية حول أنماط المناخات الأخلاقية المدركة في مختلف الجامعات الحكومية والأهلية على أن تثمل مستويات متعددة من الموظفين من

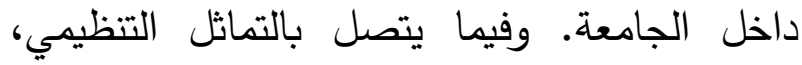
يمكن إجراء دراسات أخرى باستخدام مقاييس أخرى لئى مثل مائل وآشفورث(Mael \& Ashforth,1992) وتقنينها في البيئة الأكاديمية.

\section{المراجع العربية}

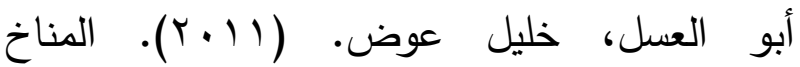
الأخلاقي وعلاقته بالاحتراق الوظيفي والالتزام التنظيمي لدى رؤساء الأقسام في مديريات التربية والتعليم (أطروحة دكتوراه غير منشورة). جامعة

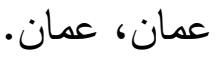

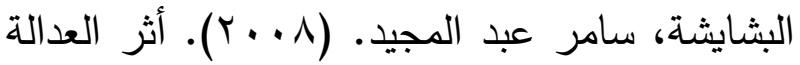
التنظيمية في بلورة التماثل التنظيمي في المؤسسات

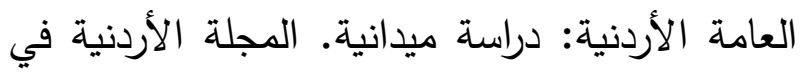

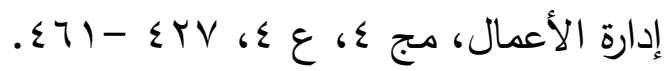
الخزاعلة، أمل راضي دخيل. (ع ا.ب). مستوى المناخ الأخلاقي السائد في المدارس الثانوية في محافظة عمان وعلاقته بدرجة تمكين المعلمين من وجهة نظرهم (رسالة ماجستير غير منشورة). جامعة الشرق الأوسط، عمان. دروزة، سوزان صالح؛ القواسمي، ديما شكري.

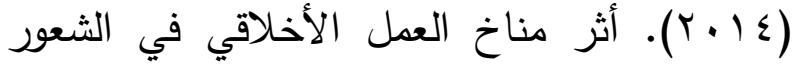
بالاغتراب الوظيفي، دراسة تطبيقية. المجلة الأردنية

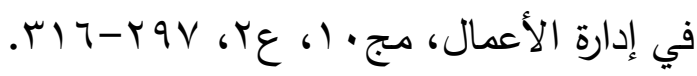


بالتطبيق على قطاع الخدمات الصحية بالمملكة العربية السعودية. دجلة البحوث المالية والتجارية،

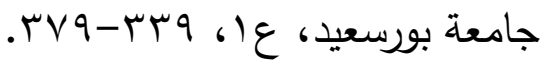

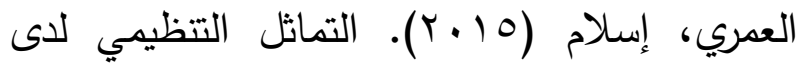
المشرفين التربويين وعلاقته بنظام الحوافز المقدم لهم. (رسالة ماجستير غير منشورة). جامعة مؤتة،

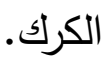
العمري، أيمن، والعموش، آية (YlV) ممارسة عمداء الكليات لمهارات الاتصال الإداري وعلاقتها بمستوي التماثل التتظيمي لدى أعضاء هيئات التدريس في الجامعات الأردنية الرسمية. مجلة اتحاد الجامعات العربية للبحوث في التعليم

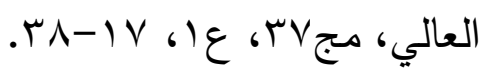

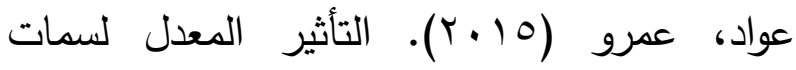
الثخصية في العلاقة بين المناخ الأخلاقي وتكتيكات إدارة الانطباعات: دراسة ميدانية. المجلة العلمية

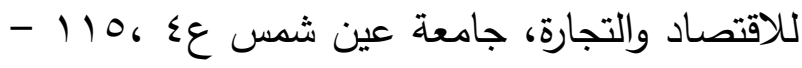
$.1 \mathrm{VT}$

القرني، محمد قحيدي. (YlV) التحويلية لدى قادة المدارس الابتدائية بمحافظة العرضيات وعلاقته بالتماثل التتظيمي لدى المعلمين

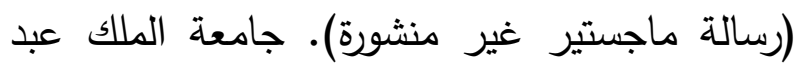

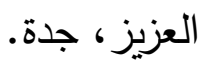

مرزوق، عبد العزيز • (r ا • ץ). نموذج مقترح لتأثير التماثل التنظيمي كمتغير وسيط على العلاقة بين أبعاد العدالة التنظيمية والارتباط الوظيفي: دراسة

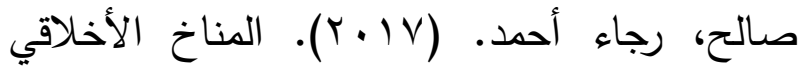

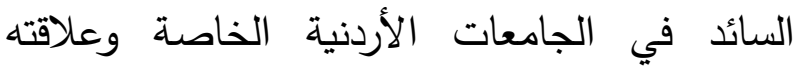

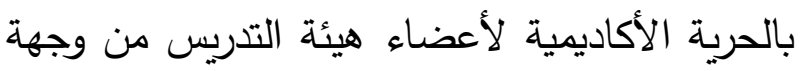
نظرهم (رسالة ماجستير غير منشورة). جامعة الشرق الأوسط، عمان. الصباغ، شوقي، ومرزوق، عبد العزيز. (r (ب).

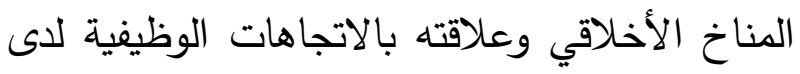
العاملين: دراسة ميدانية على مصلحة الضرائب. مجلة جامعة الأمام محمد بن سعود الاسلامية-

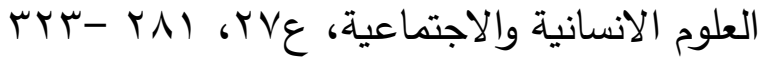

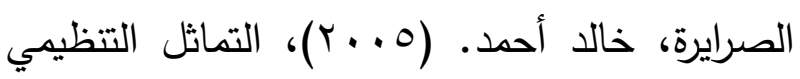
لأعضاء الهيئات التدريسية في الجامعات الأردنية الرسمية وعلاقته بشعورهم بالأمن وبأدائهم الوظيفي

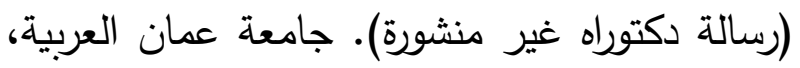

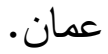

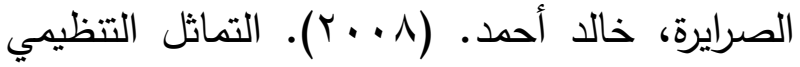
لاى أعضاء الهيئات التتريسية في الجامعات

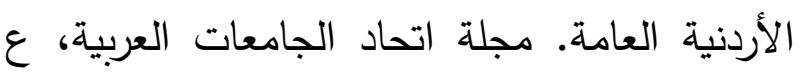
$.171-119601$ العتيبي، تركي كديميس. (1 (1 ب). التماثل التتظيمي لاى أعضاء هيئة التدريس بجامعة الطائف. مجلة لتئي

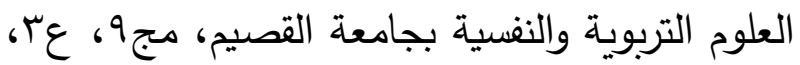
$. V T r-V .0$ العقلا، محمد علي. (10 ب ب). أثر العلاقة بين التماثل التنظيمي وإدرالك العاملين للاعم التنظيمي على تكنولوجيا الأداء البشري: دراسة ميدانية 
النسور، رانية ياسين. (1 ( • ( المناخ الأخلاقي السائد وعلاقته بالدافعية لدى أعضاء هيئة التدريس في جامعة مؤتة من وجهة نظرهم (رسالة ماجستير غير منشورة). جامعة مؤتة، مؤتة.

الوافي، مرام محمد. (T 1 • r). تأثير ممارسة القيادة التشاركية في التماثل التظظيمي لدى موظفي مكاتب التعليم بمحافظة جدة (رسالة ماجستير غير منشورة). جامعة الملك عبد العزيز ، جدة.

\section{المراجع الأجنبية}

Abrams, D., de Moura G.R. (2001). Organizational identification: Psychological anchorage and turnover In: Hogg M.A., Terry D.J., eds. Social identity processes in organizational contexts. Philadelphia, PA: Psychology Press; 2001. pp. 131-147

Al-Omari, A. (2013). The perceived organizational ethical climate in Hashemite University. The Asian Pacific Education Researcher, 22(3), 273-279. doi:http://dx.doi.org.iris.etsu.edu:2048/10.100 7/s40299-012-0033-1

Ashforth, B., \& Mael, F. (1989). Scoial identity theory and the organisation. Academy of Management Review, 14, 20--39.

Ashforth, B., Harrison, S., \& Corley, K. (2008). Identification in organizations: An examination of four fundamental questions. Journal of Management, 34(3), 325374. https://doi.org/10.1177/01492063083160 59

Borry, E. (2017). Ethical climate and rule bending: How organizational norms contribute to unintended rule consequences. Public
تطبيقية على العاملين بمديريات الخدمات بمحافظة كفر الثيخ. مجلة التجارة والتمويل، جامعة طنطا،

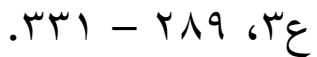

مقابلة، عاطف يوسف؛ الحوامدة، باسم علي. (11) الثانوية العامة في محافظة العاصمة عمان من وجهة نظر المعلمين. مجلة كلية التربية بجامعة عين شمس، ع"، ج"،

Administration, $\quad 95(1), \quad$ 78-96. doi:10.1111/padm.1230

Cheney, G. (1983). On the various and changing meanings of organizational membership: A field study of organizational identification. Communication Monographs, $50,342-362$.

Cole, M. and Bruch, H. (2006). Organizational identity strength, identification, and commitment and their relationships to turnover intention: does organisational hierarchy matter? Journal of Organizational Behavior, 27(5), 585-605.

Creswell, J. W. (2012). Educational Research: Planning, Conducting, and Evaluating Quantitative and Qualitative Research (4th ed.). Boston, MA: Pearson.

Cullen, J., Parboteeah, K., \& Victor, B. (2003). The effects of ethical climates on organizational commitment: A two-study analysis. Journal of Business Ethics, 46(2), 127-141. doi:405822061

Cullen, J., Victor, B. \& Stephens, C. (1989). An ethical weather report: Assessing the organization's ethical climate. Organizational Dynamics, 18(2), 50-62. 


$$
\text { صالح بن علي يعن الله القرني }
$$

Deshpande, S. (1996).The impact of ethical climate types on facets of job satisfaction: an empirical investigation. Journal of Business Ethics, 46(2), 127-141.

Deshpande, S., George, E., \& Joseph, J. (2000). Ethical climates and managerial success in Russian organizations. Journal of Business Ethics, 23(2), 211-217.

Dutton, J., Dukerich, J., \& Harquail, C. (1994). Organizational images and member identification. Administrative Science Quarterly, 39, 239-263.

Edwards, M. \& Peccei R. (2010). Perceived organizational support, organizational identification, and employee outcomes. Journal of Personnel Psychology, 9(1): 17-26.

Edwards, M. (2005). Organizational identification: A conceptual and operational review. International Journal of Management Reviews, 7(4), 207-230. http://dx.doi.org/10.1111/j.1468-

2370.2005.00114.x

Edwards, M., \& Edwards, T. (2012). Company and country effects in international mergers and acquisitions: Employee perceptions of a merger in three European countries. Economic and Industrial Democracy, 33(3), 505-529.

Edwards, M., \& Peccei, R. (2007). Organizational identification: Development and testing of a conceptually grounded measure. European Journal of Work and Organizational Psychology, 16(1),25-57. https:doi.org/10.1080/13594320601088195

Elçi, M., \& Alpkan, L. (2009). The impact of perceived organizational ethical climate on work satisfaction. Journal of Business Ethics, 84(3), 297-311. https://doi.org/10.1007/s10551-008-9709-0
Holzinger I, Dhalla R. (2007).Multiple Identities in Organizations: The effects of diversity on organizational identity. Diversity Journal. 7(5):43-51.

Johnson, M., Morgeson, F. \& Hekman, D. (2012).Cognitive and affective identification: Developing a new measure and exploring the links between different forms of social identification and personality with work attitudes and behavior. Journal of Organizational Behavior, 33(8), 1142-1167.

Joseph, J. \& Deshpande, S. (1997).The impact of ethical climate on job satisfaction of nurses. Health Care Management Review, 22(1), 7681.

Kohlberg, L. (1984). The Psychology of Moral Development. San Francisco: Harper \& Row.

Kovoor-Misra, S., \& Smith, M. (2011). Artifacts, identification and support for change after an acquisition. Leadership \& Organization Development Journal, 32(6), 584-604.

Mael, F., \& Ashforth, B. (1992). Alumni and their alma mater: A partial test of the reformulated model of organizational identification, Journal of Organization Behavior, 13 (2), 103-123.

Mael, F., \& Ashforth, B. (2001). Identification in work, war, sports, and religion: Contrasting the benefits and risks. Journal for the Theory of Social Behaviour, 31(2), 196-222.

Martin, K. \& Cullen, J. (2006). Continuities and extensions of ethical climate theory: A meta-analytic review. Journal of Business Ethics, 69(2), 175-194 .

Merton, R. K. (1957). Social Theory and Social Structure. New York: Free Press. 
Meyer, J., \& Allen, N. (1997). Commitment in the workplace: theory, research, and application. Thousand Oaks, CA: Sage Publications

Meyer, J., Becker, T., \& Van Dick, R. (2006). Social identities and commitments at work: Toward an integrative model. Journal of Organizational Behavior, 27(5), 665-683. http://dx.doi.org/10.1002/job.383

Miller, V., Allen, M., Casey, M., \& Johnson, J. (2000). Reconsidering the Organizational Identification Questionnaire, Management Communication Quarterly, 13 (4), 626-658.

Moore, H. L. (2012). Ethical climate, organizational commitment, and job satisfaction of full-time faculty members. Electronic Theses and Dissertations. Paper 1407. https://dc.etsu.edu/etd/1407

Moore, L. and Moore, W. (2014).The effect of ethical climate on organizational commitment of faculty members. Journal of Academic and Business Ethics, 9(-), 1-15.

Mulki, J., Jaramillo, F. \& Locander, W. (2006). Effects of ethical climate and supervisory trust on salesperson's job attitudes and intentions to quit. Journal of Personal Selling \& Sales Management, 26(1), 19-26.

Mulki, J., Jaramillo, F. \& Locander, W. (2008). Effect of ethical climate on turnover intention: linking attitudinal and stress theory. Journal of Business Ethics 78, 559-574.

Peterson, D. K. (2002a). Deviant workplace behavior and the organization's ethical climate. Journal of Business and Psychology, 17(1), 47-61.

Peterson, D. K. (2002b). The relationship between unethical behavior and the dimensions of the ethical climate questionnaire. Journal of Business Ethics, 41, 313-326.

Pratt, M.G. (1998). To Be or Not To Be? Central Questions in Organizational Identification, pp. 171-207 in D.A. Whetten \& Godfrey, P.C. (eds.), Identities in Organizations: Building Theory Through Conversations, Thousand Oaks: Sage.

Putranta, M. P. (2008). The relationships between ethical climates, ethical ideology, and organizational commitment (Dissertation). University of Notre Dame Australia.

Putranta, M., \& Kingshott, R. (2011). The Relationships between Ethical Climates, Ethical Ideologies and organisational Commitment within Indonesian Higher Education Institutions. Journal of Academic Ethics, 9(1), 43-60 .

Reade, C. (2001). Antecedents of organizational identification in multinational corporations: fostering psychological attachment to the local subsidiary and the global organization. International Journal of Human Resource Management, 12 (8), 12691291.

Riketta, M., \& Van Dick, R. (2005). Foci of attachment in organizations: A meta-analysis comparison of the strength and correlates of work-group versus organizational commitment and identification. Journal of Vocational Behavior, 67 (3), 490-510

Schneider, B., \& Reichers, A. (1983). On the etiology of climates. Personnel Psychology, 36(1), 19-39. http://dx.doi.org/10.1111/j.17446570.1983.tb00500.x

Scott S., \& Lane, V. (2000). A stakeholder approach to organizational identity. Academy of Management Review, 25(1),43-62 


$$
\text { صالح بن علي يعن الله القرني }
$$

Sert, A., Elçi, M., Uslu, T. \& Şener, I. (2014). The effects of organizational justice and ethical climate on perceived work-related stress. Procedia-Social and Behavioural Sciences, 150, 1187-1198

Taşdan, M. (2015).Elementary school teachers' perception of organizational identification. Education and Science, 40(180), 327-342.

Tsai, M. \& Huang, C. (2008). The relationship among ethical climate types, facets of job satisfaction, and the three components of organizational commitment: a study of nurses in Taiwan. Journal of Business Ethics, 80, 565-581.

Ulrich, C., O'Donnell, P., Taylor, C., Farrar, A., Danis, M. \& Grady, C. (2007). Ethical climate, ethics stress, and the job satisfaction of nurses and social workers. Social Science and Medicine. 65(8), 1708-1719.

Van Dick, R. (2001). Identification in organizational contexts: Linking theory and research from social and organizational psychology. International Journal of Management Reviews, 3(4), 265-283 .

Van Dick, R., Hirst, G., Grojean, M., \& Wieseke, J. (2007). Relationships between leader and follower identification and implications for follower attitudes and behaviors, Journal of Occupational and Organizational Psychology, 80 (1), 133-150.

Van Knippenberg, D., \& Van Schie, E. C. M. (2000). Foci and correlates of organizational identification. Journal of Occupational and Organizational Psychology, 73(2), 137- 147.http://dx.doi.org/10.1348/0963179001669 49.

Victor, B., \& Cullen, J. (1987). A theory and measure of ethical climate in organizations. Research in Corporate Social Performances and Policy, 9 (1), 51-71.

Victor, B., \& Cullen, J. (1988). The organizational bases of ethical work climates. Administrative Science Quarterly, 33(1), 101125. http://dx.doi.org/10.2307/2392857

Victor, B., \& Cullen, J. (1993). The ethical climate questionnaire: an assessment of its development and validity. Psychological Reports, 73(2), 667-674 .

Vuuren, M., Beelen, P., \& Jong, M. D. T. (2010). Speaking of dominance, status differences, and identification: Making sense of a merger. Journal of Occupational and Organizational Psychology, 83(3), 627-643.

Wang, Y., \& Hsieh, H. (2013). Organizational ethical climate, perceived organizational support, and employee silence: A cross-level investigation. Human Relations, 66(6), 783802.

https://doi.org/10.1177/0018726712460706

Weber, J.(1995). Influences upon organizational ethical subclimates: a multidepartmental analysis of a single firm. Organizational Science, 6(5), 509- 523.

Wimbush, J., Shepard, J., \& Markham, S. (1997). An empirical examination of the relationship between ethical climate and ethical behavior from multiple levels of analysis. Journal of Business Ethics, 16, 17051716. 
المناخ الأخلاقي وعلاقته بالتماثل التنظيمي لدى أعضاء هيئة التدريس بجامعة الملك عبد العزيز

\title{
The Relationship between Ethical Climate and Organizational Identification among Teaching Faculty at King Abdulaziz University
}

\begin{abstract}
Salih Aly Al-Garni
Abstract. this study aimed to explore the relationship between perceived ethical climate and organizational identification among teaching faculty at King Abdulaziz University. In addition, the study aimed to analyze the influence of ethical climate on faculty's organizational identification. Findings indicated that different types of ethical climate do exist in the university. Out of the five climes, two types, namely laws and rules, exist at a high degree, whereas care, independence and instrumental climates exist at a moderate degree. The study found a high degree of organizational identification among teaching faculty in general and in its three dimensions as well. The findings showed that laws, rules and care climates were positively related to faculty's organizational identification. Out of the five climates, care climate was alone accounted for approximately $50.2 \%$ of the variation in organizational identification among teaching faculty.

Keywords: ethical climate, organizational identification, teaching faculty
\end{abstract}

